\title{
Numerical Simulation of Debris Flow Runout Using Ramms: A Case Study of Luzhuang Gully in China
}

\author{
Jianjun Gan ${ }^{1,2}$ and Y. X. Zhang ${ }^{2, *}$
}

\begin{abstract}
This study proposes a comprehensive method, which consists of field investigation, flume test and numerical simulation, to predict the velocity and sediment thickness of debris flow. The velocity and sediment thickness of the debris flow in mountainous areas can provide critical data to evaluate the geohazard, which will in turn help to understand the debris runout. The flume test of this debris prototype can provide friction coefficient and viscosity coefficient which are important for numerical simulation of debris flow. The relation between the key parameters in the numerical modelling using the Voellmy model and debris-flow rheology is discussed. Through simulation of a debris flow that occurred in Luzhuang gully, it is observed that the debris flow runout determined by the Voellmy model was well consistent with that obtained from field investigation and flume test, demonstrating the effectiveness of this study. The relationship between the Voellmy model and debris flow runout is also proposed.
\end{abstract}

Keywords: Simulation approach, debris flow, flume test, Voellmy model, Luzhaung gully.

\section{Introduction}

Debris flow in mountainous areas possesses a huge threat to people and properties and has been a major concern around the globe. In China, about 74 million people live in lowmedium mountain areas, who are at the risk of mudslides, and more than 100 cities and towns are exposed to debris flow [Cui, Zhou and Guo (2000)]. According to statistics, from 2012 to 2018, 33, 524 debris flows occurred in China [Guan, Shen and Zhuang (2018)]. Actually mudslides have been found on every continent except Antarctica, and they pose a significant hazard in the mountains of the European Alps, the Himalayan region of Asia, the Pacific coast mountains of North and South America, and some mountains in the interior of the continents of Europe, Asia, and the United States [Hassan, Hogan and Bird (2005); Harris, Arenson and Christiansen (2009); Azam, Wagnon and Berthier (2018)]. Due to extreme rainfall and effect of gravity, debris flows usually accelerate their descent and follow steep mountain trenches to alluvial fans or floodplains, often resulting in catastrophic events at the downstream community [Hungr, Leroueil and

\footnotetext{
${ }^{1}$ Jiangxi Engineering Research Center of Water Engineering Safety and Resources Efficient Utilization, Nanchang Institute of Technology, Nanchang, China.

${ }^{2}$ School of Computing, Engineering and Mathematics, Western Sydney University, NSW, 2751, Australia.

${ }^{*}$ Corresponding Author: Y. X. Zhang. Email: sarah.zhang@westernsydney.edu.au.
} 
Picarelli (2014)]. For instance, the local heavy rainfall due to the storm in Xiushui county, north Jiangxi province, China on June 9-10, 2011 caused the massive Luzhuang gully debris flow, with the total volume of $25.13 \times 10^{4} \mathrm{~m}^{3}$, which caused a significant amount of damage to the riverside facilities (e.g., 260 acres of farmland, 8 bridges, $3 \mathrm{~km}$ highway, 5 $\mathrm{km}$ river embankment, 26 water weirs, and 39 houses) [Gan, Yuan and Li (2017)].

For better prevention and mitigation of disasters, since the 1960s, in-depth and systematic studies on the formation mechanism of gully debris flow in mountainous areas have been conducted worldwide [Xiong, Wang, Li et al. (2016); Hu, Lei, Hu et al. (2018)]. Numerical simulations have been conducted to predict debris flow hazard and risk zonation, and it was found that the run-out distances, sediment depth and impact pressure were the key factors for predicting debris flow [Van Westen, Van Asch and Soeter (2006); Jakob and Hungr (2005); Liu, Nakatani and Mizuyama (2013); Fan, Lehmann, McArdell et al. (2017); Lombardo, Opitz and Huser (2018)]. The physical debris flow runout models are often used as empirical methods to predict the three key factors. However, the mathematical models adopted in the different numerical simulation methods are different, with different basic theories, calculation formulas and equations. For instance, different fundamental assumption simulations (single-phase or multi-phase, discrete of continuous model, et al.) have been used to estimate the debris flow behavior [Konzuk and Kueper (2004); Baum and Godt (2010); Dumbser and Toro (2011); Schraml, Thomschitz and McArdell (2015); Chen, Zong and Li (2017); Han, Su, Li et al. (2019)]. Different numerical methods and schemes (e.g., FEM, FVM, FDM, DEM, $\mathrm{SPH}, \mathrm{SWE}$ et al.) and constitutive models (e.g., Bingham, HBP, Voellmy, Cross, Viscous et al.) were used to analyze the flow behaviour and runout of the complex debris flow [Voellmy (1995); Cannon, Kirkham and Parise (2001); Bertolo and Wieczorek (2005); Malet, Rematre and Maquaire (2005); Medina, Huerlimann and Bateman (2008); Domnik, Pudasaini, Katzenbach et al. (2013); Han, Chen, Li et al. (2015b); Vagnon, Pirulli and Yague (2019)] .

At present, it is difficult to elucidate the velocity, deposition depth and movement distance of gully debris flow, which are often critical and associated with the monitoring, warning and prevention of debris flow. A considerable number of debris flows have occurred in gullies with relatively gentle slopes $(<300 \%)$, and such gullies are stable even under rainstorm conditions and have been calculated using the commonly used rainflood method and other normative calculation formulas. Debris flow caused by local heavy rainfall is attributed to the huge pore water pressure with the sudden rise in the groundwater level during the rainstorm, and this has been considered in some research, increasing the instability and accelerating slippage of the rock and soil mass in the gully. However, in some debris flow areas, no groundwater seeps from the drainage holes were placed near the surface during rainstorms, and the monitored results also indicated that the groundwater level near the surface was not sensitive to rainstorms [Rickenmann and Zimmermann (1993); Dai, Lee and Wang (1999); Chen, Zhou and Yang (2010); Cui, Zhou and Guo (2017); Laura, David, Antonino et al. (2017); Papa, Sarno and Vitiello (2018); Scaringi, Fan, Xu et al. (2018)].

To elucidate the movement process of gully debris flow and predict the movement distance and effect range of debris flow, many researchers attempted the numerical 
models in soft tools such as RAMMS-Debris Flow, DAN3D, SPH and Massflow, to estimate its movement parameters [Frank, McArdell, Huggel et al. (2015); Vasu, Lee, Lee et al. (2018); Liu, He and Ouyang (2017)]. Among them, the two-parameter Voellmy friction model was primarily used in RAMMS software to describe the friction behavior between flowing debris. It was found that the Voellmy friction model was capable of accurately simulating the remote movement of debris flow [Christen, Kowalski and Bartelt (2010)]. To calibrate the Voellmy model in RAMMS software, it is often necessary to refer to well-documented historical events to determine the optimal set of fitting parameters that can be used in subsequent analyses. Besides, RAMMS software is also capable of exporting the results to GIS, modifying topographic data (e.g., previous modeling problems and structural migration measures), increasing additional parameters (e.g., yield stress), and enhancing prediction effect of the debris flow [Berger, Christen and Speerli (2016); Ouyang, He and Tang (2017)]. However, these studies have not been verified by practical debris flows. Gully debris flows are different from slope debris flows for their longer channeling, larger volume and larger flow depth, which may carry huge particles and plant roots.

This paper aims to study the movements of debris flow that occurred in Luzhuang gully, Huanglong township, Xiushui district, Jiangxi province in 2014. Using the relevant parameters from field investigation and laboratory experiments, the Voellmy friction model in RAMMS was used to simulate the variation of movement velocity and deposition thickness in the key sites. Subsequently, the results of the model test to determine the scope of potential risk area of debris flow and the impact of specific disasters were compared and analyzed. Finally, the dynamic characteristics and moving features at the key parameter section caused by rainfall-induced debris flow is proposed.

\section{Methodology}

\subsection{Governing equations}

The Voellmy model which was originally proposed for snow avalanches [Voellmy (1955)], is based on the assumption of the debris flow fluid as a single-phase model. It can be characterized by two-fluid parameters, i.e., fluid height $H(x, y, t)(\mathrm{m})$ and mean velocity $U(x, y, t)(\mathrm{m} / \mathrm{s})$, which is given by

$U(x, y, t)=\left[U_{x}(x, y, t), U_{y}(x, y, t)\right]^{T}$

where $U_{x}$ denotes the velocity in $\mathrm{X}$ direction, $U_{y}$ is the velocity in $\mathrm{Y}$ direction, and $\mathrm{T}$ is the symbol for the transpose of the average velocity [Bartelt, Salm and Gruber (1999)]. The magnitude of the velocity can be defined as

$\|U\|=\sqrt{U_{X}^{2}+U_{Y}^{2}}$

In Eq. (2), $\|U\|$ means that the absolute average value of $U$ is taken, which can ensure that $U$ to a strict positive velocity in the vector space. The direction of the fluid velocity is defined by the unit vector $\left(n_{u}\right)$ : 
$n_{u}=\frac{1}{\|U\|}\left(U_{X}, U_{Y}\right)^{T}$

Voellmy rheological model is expressed by the following mass balance equation:

$\partial_{t} H+\partial_{x}\left(H U_{x}\right)+\partial_{y}\left(H U_{y}\right)=Q(x, y, t)$

where $\mathrm{H}(\mathrm{x}, \mathrm{y}, \mathrm{t})$ denotes the flow height $(\mathrm{m})$, and $Q(x, y, t)$ is the mass production source term $(\mathrm{m} / \mathrm{s})$. When $\mathrm{Q}>0$, it is called entrainment rate; when $\mathrm{Q}=0$, there is no material erosion/deposition; when $\mathrm{Q}<0$, it denotes the deposition rate [Christen, Kowalski and Bartelt (2010)].

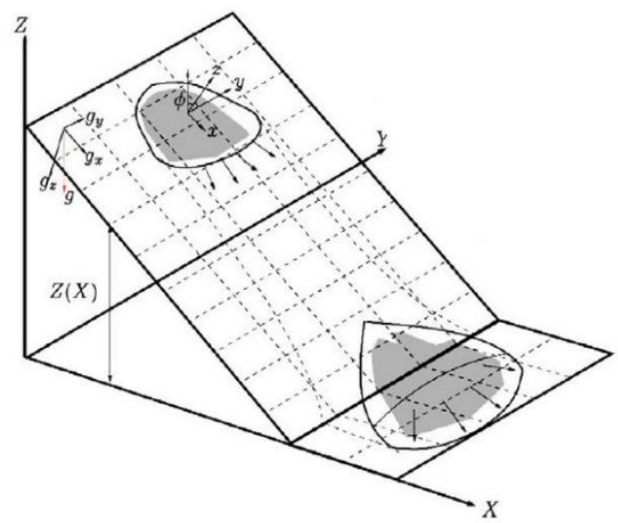

Figure 1: Reference system and Voellmy model

In $X$ and $Y$ directions as shown in Fig. 1, the average depth equilibrium equation of the fluid is expressed as:

$\partial_{t}\left(H U_{x}\right)+\partial_{x}\left(C_{x} H U_{x}^{2}+g_{z} k_{a / p} \frac{H^{2}}{2}\right)+\partial_{y}\left(H U_{x} U_{y}\right)=S_{g x}-S_{f x}$

and

$\partial_{t}\left(H U_{y}\right)+\partial_{y}\left(C_{y} H U_{y}^{2}+g_{z} k_{a / p} \frac{H^{2}}{2}\right)+\partial_{x}\left(H U_{x} U_{y}\right)=S_{g y}-S_{f y}$

where $C_{x}$ and $C_{y}$ denote the profile coefficient; $g_{z}$ is the gravity acceleration in the vertical direction; $S_{\mathrm{gx}}=\mathrm{g}_{\mathrm{x}} H, S_{f x}=g_{\mathrm{y}} H$ denotes the driving, gravitational acceleration in $\mathrm{x}$ and y direction, respectively; $S_{\mathrm{fx}}, S_{f y}$ denote the friction of driving, gravitation acceleration in $\mathrm{x}$ and $\mathrm{y}$ direction, respectively, which could be given by:

$\mathrm{S}_{f x}=n_{U_{x}}\left[\mu g_{z} \mathrm{H}+\frac{g\|U\|^{2}}{\xi}\right]$ and $\mathrm{S}_{f y}=n_{U_{y}}\left[\frac{\mu g_{z} \mathrm{H}+g\|U\|^{2}}{\xi}\right]$

In the Voellmy model, the contact relationship in the vertical direction can be defined as the heterogeneous Mohr-Coulomb relationship [Christen, Kowalski and Bartelt (2010)], 
where " $\mu$ " is the dry friction coefficient, $\xi$ is the "viscous" or "turbulent" friction coefficient; $n_{U_{x}}$ is the velocity directional unit vectors in $\mathrm{x}$ direction, $n_{U_{v}}$ is the velocity directional unit vectors in y direction, and $k_{a / p}$ is the earth pressure coefficient, which is expressed as:

$k_{a / p}=\tan ^{2}\left[45^{\circ} \pm \frac{\varphi}{2}\right]$

where $\varphi$ denotes the internal friction, and $k_{a / p}$ denotes the active/passive proportionality of the earth pressure. Active area refers to the dilatant flow region $\nabla \cdot U \geqslant 0$ and passive area refers to the compressive region $\nabla \cdot \mathrm{U}<0$ [Christen, Kowalski and Bartelt (2010)]. Moreover, besides the Rankine theory, other approaches such as that used by Savage and Hutter (1989) have been employed for estimating the earth pressure coefficient [Savage and Hutter (1989)].

The Voellmy-fluid formula can be obtained through the above-mentioned methods:

$\frac{d\left(U_{h}\right)}{d t}=(z \cdot n) n h-k(\nabla h) h-\left[\mu^{\prime}(z \cdot n) h+\frac{1}{\xi} U^{2}\right] s$

where variables are measured separately with length $\mathrm{L}$, velocity $(\mathrm{gl}) / 2$ and time $(\mathrm{L} / \mathrm{g}) / 2$ to obtain a unified Froude value; $k, \mu^{\prime}$ and $\mathrm{s}$ denotes the anisotropic set of lateral earth pressure ratios, the effective dynamic friction coefficient and moving direction, respectively; Gravity vector is $z=(0,0,-1)$, and the disturbance coefficient is defined by $\zeta=\frac{\xi}{g}$, which is dimensionless.

By sorting out Eq. (9) for gravity flow, the following equation for calculating the internal resistance of fluids in the viscous flow of gravity rock-soil mass can be obtained:

$$
\begin{aligned}
& S=\mu \rho h g \cos (\varphi)+\frac{\rho g U^{2}}{\xi}+(1-\mu) N_{0}-(1-\mu) e^{\frac{-\mu \rho h g \cos (\varphi)}{N_{0}}} \\
& =\mu N++\frac{\rho g U^{2}}{\xi}+(1-\mu) N_{0}-(1-\mu) e^{-\frac{N}{N_{0}}}
\end{aligned}
$$

where $N_{0}$ is the yield stress of debris flow materials. In this case, we introduce the parameter $\mathrm{N}=\rho g u \cos (\varphi)$ and $\mu$ a "hardening" parameter to model ideal plastic material. The second parameter $\frac{\rho g u^{2}}{\xi}$ is the viscous stress and the third parameter $(1-\mu) N_{0}-(1-\mu) N_{0} e^{-\frac{N}{N_{0}}}$ is the shear stress of the flow material. At low normal pressure (small flow heights), the shear stress increases rapidly from $S=0$ to $S=N_{0}$. The 
slope of the "S $v s$. N" relation remains $\mu$, when the normal pressures $\mathrm{N}$ are large. If $\mu=0$, it has a Visco-pasic behaviour.

The RAMMS-DF software developed by Eidgenössische Technische Hochschule Zürich, is based on the concept of equivalent fluid [Hungr (1995)] and the assumption that the density and compressibility of the flow medium remain unchanged. In this case, the two parameters ( $\mu$ and $\xi$ ) of the Voellmy friction model are capable of describing the friction behavior between debris flow deposits, thereby accurately simulating the highspeed and remote movement of debris flow materials. To calibrate the Voellmy model, it is often necessary to refer to well-documented historical events to determine an optimal set of fitting parameters that can be used in subsequent analyses [Veollmy (1955)]. Furthermore, RAMMS software can also export the results to GIS and correct the terrain data (e.g., previous modeling problems and structural migration measures). This helps engineers assess the impact or mitigation of previous flows and predict future flows.

\subsection{Friction parameters}

The frictional resistance of the Voellmy's rheological model is controlled by two parameters $\mu$ and $\xi$, where $\mu$ denotes the dry friction coefficient or the base friction (Coulomb friction) related to the normal stress $\mathrm{N}$ usually expressed as the tangent of the internal shear angle, and $\xi$ is viscosity/turbulence coefficient, or internal friction (viscous turbulent friction) associated with the square of the velocity $u^{2}$.

According to Christen et al. [Christen, Kowalski and Bartelt (2010)], if the water content of the debris flow is less than 5\% Eq. (10) can be simplified as:

$S=\mu N+\frac{\rho g u^{2}}{\xi}, \quad N=\rho h g \cos (\varphi)$

where $\rho$ denotes the density; $g$ denotes the acceleration of gravity; $\varphi$ denotes the angle of inclination; h denotes the height of the debris flow; and $u=\left(u_{x}, u_{y}\right)^{T}$. From Eq. (11), the velocity $u^{2}$ has a direct effect on the internal resistance $\mathrm{S}$ of the debris flow, and the viscosity/turbulence coefficient $\xi$ plays a leading role when the velocity is relatively high.

\subsection{Determination of friction parameters}

In the Voellmy friction model, the debris flow is considered as a single-phase model, and all materials are considered as a whole flow without distinguishing between fluid and solid phase materials. However, the material composition of the actual debris flow is very complex, and the most challenging task in simulating debris flow movement using RAMMS is to select appropriate friction parameter, so that it could simulate the local debris flow movement better. The selection and correction of the friction parameters are the keys to the RAMMS numerical simulation [Kocyigit and Gürer (2007)]. The values of friction parameters have an obvious effect on the numerical simulation results [Bezak, Sodnik and Mikos (2019)]. To calculate and correct the value of the friction parameters, the comprehensive motion characteristics of the debris flow erosion process in the model 
test site should be considered.

The scope, thickness and base friction parameters of debris flow simulation are preliminarily determined by combining with monitoring data, image data and final scope of debris flow disaster. Subsequently, the flow velocity, deposition height, accumulation distribution, flow velocity, and the flow path of debris flow development of debris flow materials are estimated. Finally, the friction parameters are calibrated under the local engineering conditions.

Table 1: Main parameter similarity ratio of rainfall model

\begin{tabular}{|c|c|c|c|c|c|c|c|c|c|c|}
\hline \multirow[b]{2}{*}{ Source } & \multirow[b]{2}{*}{$\begin{array}{l}\text { Density } \\
\left(\mathrm{g} / \mathrm{cm}^{3}\right)\end{array}$} & \multirow[b]{2}{*}{$\begin{array}{l}\text { Water } \\
\text { moisture } \\
(\%)\end{array}$} & \multirow[b]{2}{*}{$\begin{array}{l}\text { Cohesion } \\
\mathrm{c}(\mathrm{kPa})\end{array}$} & \multirow[b]{2}{*}{$\begin{array}{l}\text { Friction } \\
\text { angle }\left({ }^{\circ}\right)\end{array}$} & \multirow[b]{2}{*}{$\begin{array}{l}\text { Permeability } \\
\text { coefficient } \\
(\mathrm{cm} / \mathrm{s})\end{array}$} & \multirow{2}{*}{$\begin{array}{l}\text { Modulus } \\
\text { of } \\
\text { compres } \\
\text { sibility } \\
\text { (MPa) }\end{array}$} & \multicolumn{4}{|c|}{ Grain composition (\%) } \\
\hline & & & & & & & $\begin{array}{l}\geq 0.5 \\
\mathrm{~mm}\end{array}$ & $\begin{array}{l}0.2-0.5 \\
\mathrm{~mm}\end{array}$ & $\begin{array}{l}0.074- \\
0.2 \mathrm{~mm}\end{array}$ & $\begin{array}{l}\leq 0.07 \\
4\end{array}$ \\
\hline $\begin{array}{l}\text { Protot } \\
\text { ype }\end{array}$ & 2.63 & 26.4 & 17.42 & 32.2 & $2.1 \times 10^{-5}$ & 5.40 & 90.5 & 5.7 & 2.8 & 1.0 \\
\hline Model & 2.62 & 26.5 & 0.18 & 22.3 & $2.2 \times 10^{-6}$ & 0.05 & 6.46 & 51.87 & 31.78 & 9.89 \\
\hline
\end{tabular}

Drilling and sampling of sliding body materials and laboratory soil shear tests were carried out during the investigation of the debris flow. Based on the geometric, kinematic and dynamic similarity, the density, water moisture permeability between the prototype and model were set to be similar, but the cohesion, modulus of compressibility in laboratory tests were set with different parameters [Iverson(1997)]. Due to the complexity and non-uniformity of the surface, the friction resistance cannot be directly obtained from the test, so it is taken as a variable and obtained by the flume test. By comparing the simulated movement process and accumulation pattern of debris flow with the actual accumulation pattern of debris flow, the values of simulation parameters for the debris flow in Luzhuang gully are shown in Tab. 1.

\section{Input parameters}

\subsection{Input method}

RAMMS was used for numerical analysis of the debris flow, and Digital Elevation Model (DEM) was used as the topographic data for modeling. RAMMS pretreatment directly affects the accuracy of numerical simulation results of the debris flow such as determination of calculation domain and release region, release mode, digital elevation model, and the value and correction of friction parameters. DEM and friction parameters ( $\mu$ and $\xi$ ) are most critical for the numerical analysis of debris flow DEM file is the most important input data in the pre-processing of numerical simulation, which can accurately reflect the notable topographic features of the debris flow. 


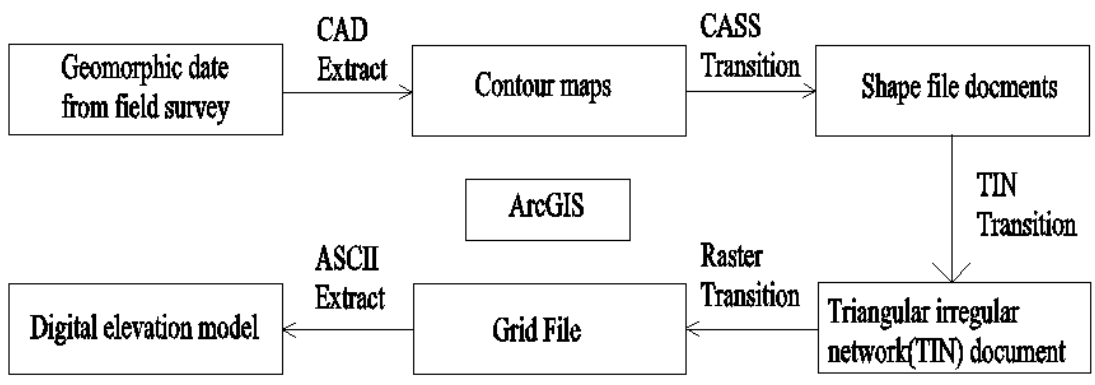

Figure 2: Complex digital elevation model generation
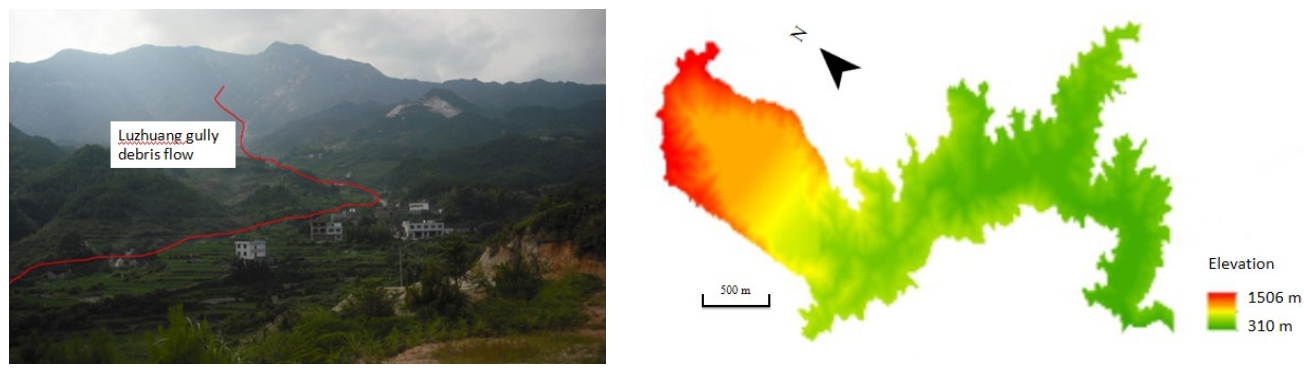

Figure 3: Photo and DEM model of Luzhuang gully debris flow

The DEM model adopted the satellite topography bounded by the watershed of debris flow basin with a resolution of $2 \mathrm{~m}$. ArcGIS software was used to generate the topography of the model, and CASS software was used to generate the profile to form topographic data files and profile files. The generation process of the debris flow is illustrated in Fig. 2. Shapefile, triangular network file and raster file of the research area were generated via the ArcGIS platform sequentially, and ASCII extraction of raster file was performed. Subsequently, DEM files of debris flow research area under complex terrain conditions were generated, as shown in Fig. 3.

To analyze the impact of debris flow caused by landslides on the downstream, first the Voellmy friction coefficients were calibrated by back-calculating a granular-type small event at Luzhaug gully, Huanglong town (Jiangxi province, China), and then the starting conditions, namely the block release (all debris material is accelerated at once) were applied by analyzing the resulting discharge curves at a specific location [Voellmy (1955)]. Finally, the input shape file (inflow of material is controlled according to a given discharge topography) was imported during the modeling process to define the total volume of material sourced in the release area of debris flow accumulation body.

\subsection{Parameter calibration}

By comparing the results of the laboratory flume test and numerical simulation, the flow change and deposition range of the downflow debris flow were comprehensively considered, the final deposition height of the monitoring point was compared, and the friction parameters of the numerical simulation were fitted and calibrated [Valentino, Barla 
and Montrasio (2008); Luna, Remaitre, Van Asch et al. (2012); Kang and Chan (2018)].

The flume test physical model is shown in Fig. 4(a), with the model geometry size of 50 $\mathrm{m} \times 0.6 \mathrm{~m} \times 3 \mathrm{~m}$, and the release area of a geometry size of $1.6 \mathrm{~m} \times 0.6 \mathrm{~m} \times 0.5 \mathrm{~m}$, and the slope of $40^{\circ}$. Because the release area in the prototype was about $160 \mathrm{~m}$ and the similarity scale was 100 so that the length of the resource in the physical model was set as $1.6 \mathrm{~m}$ and the release area source volume was $0.55 \mathrm{~m}^{3}$. The DEM file was generated by ArcGIS software developed by ESRI. The purpose of this model study is to obtain the dry friction coefficient and viscosity coefficient of the substrate. The flow test model adopted in this test is shown in Fig. 4(b).

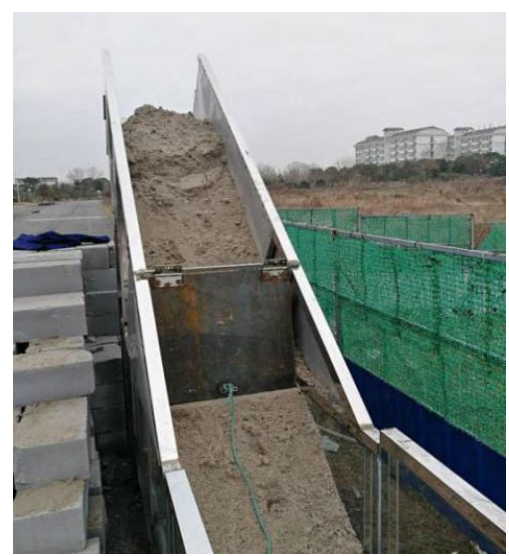

(a)

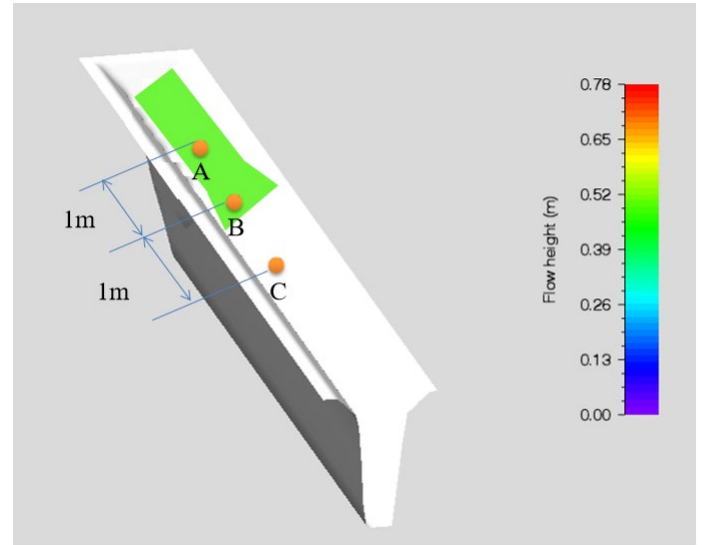

(b)

Figure 4: The laboratory flume test model (a) and numerical simulation schematic diagram of the flume test (b)

According to the principle of similarity ratio [Richard, Mark and Richard (1997)], the ratio of prototype materials to model test materials is based on the principle of heavy similarity. The specific ratio parameters are shown in Tab. 1.

\subsubsection{Sediment height and cross-section flow rate of debris flow change $(t=1 \mathrm{~s})$}

As shown in Fig. 5, the grey area denotes the flow height (Deposition depth)(the left axis), the red line is the active parameter (multiplied by 50) added to the track profile (altitude, scale on the right side), and the green line is the topography in the section (right axis). When $t=1 \mathrm{~s}$, the variation of deposition height of debris flow was small on both sides, with the greatest deposition height of flow rock in the middle, which was about $0.73 \mathrm{~m}$, and less height on both sides, which was about $0.11 \mathrm{~m}$. The flow volume at the section was $0.15 \mathrm{~m}^{3}$. The red line of the flow rate curve indicates that the debris flow starts and keep moving. 


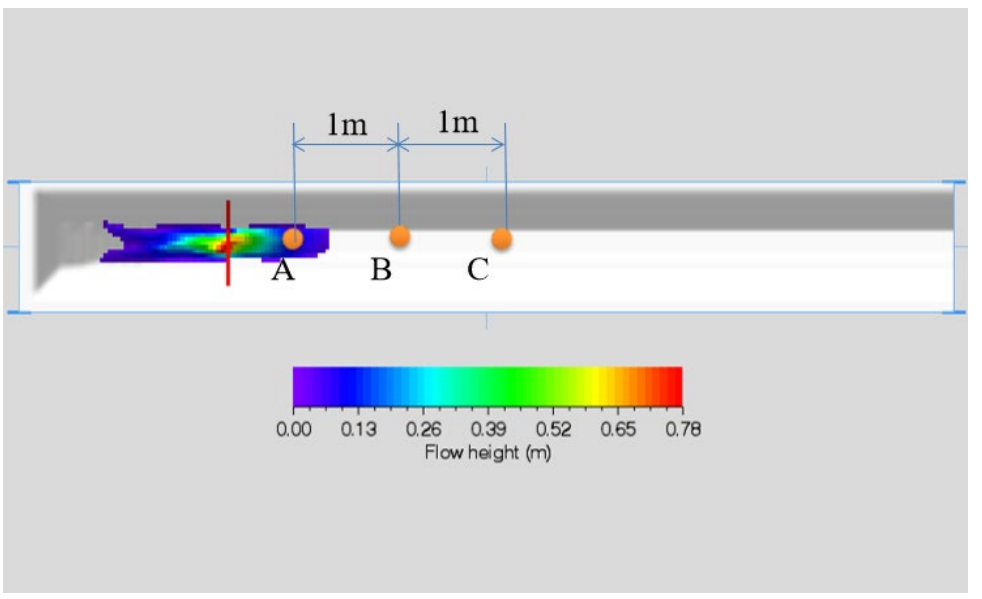

(a)

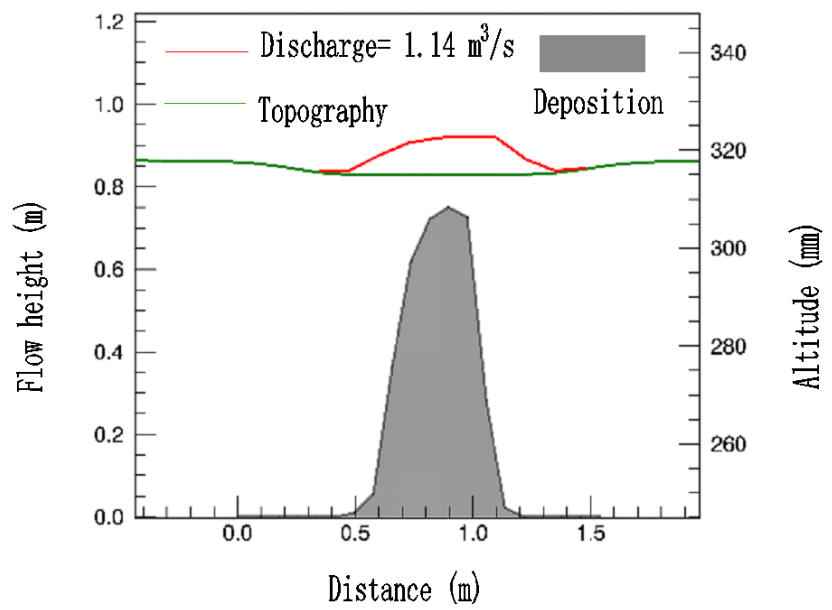

(b)

Figure 5: The numerical simulation deposit chart of flume test (a) and the flow chart section of the flume test at the red line (b) $(t=1 \mathrm{~s})$

\subsubsection{Sediment height and cross-section flow rate of debris flow change ( $t=2 \mathrm{~s})$}

As shown in Fig. 6, when time $=2 \mathrm{~s}$, the simulation test of the flow groove was almost completed. The variation of the deposition height of debris flow in the flow groove showed that the deposition height of debris flow was small on both sides and large in the Point $\mathrm{B}$, the deposition height of debris flow in the middle was about $0.24 \mathrm{~m}$, and the deposition height of debris flow on both sides was about $0.06 \mathrm{~m}$. Debris flow almost flew through the section, and the flow volume at the section was $0.02 \mathrm{~m}^{3}$. 


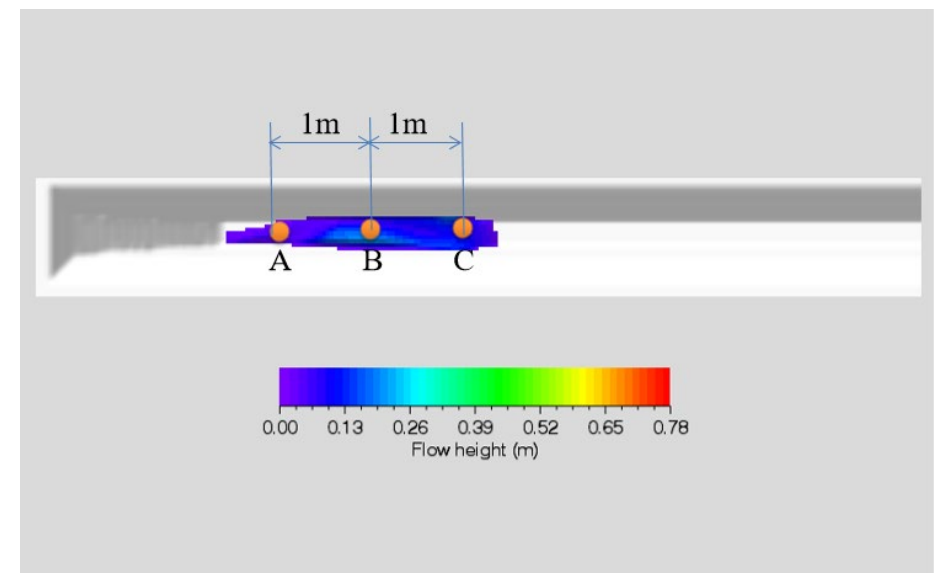

(a)

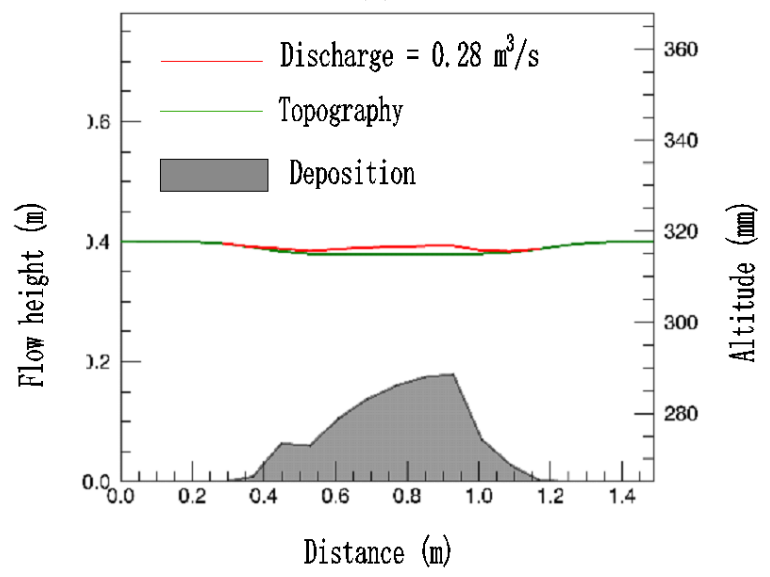

(b)

Figure 6: (a) flow height chart section of the flume test at the red line; (b) flow chart section of the flume test at the Point B $(t=2 \mathrm{~s})$

Since the friction parameters in RAMMS are based on the Voellmy friction model, two friction parameters, i.e., dry friction coefficient and "sticky", "turbulence" type coefficient are deduced. In a debris flow, the materials in the fluid are very complex, and the friction coefficients of different materials are also different. To simplify the simulation, RAMMS regards the debris flow as a monometric mean mixture, and the friction parameters used in the analysis are constant in space and time. So, the dry friction coefficient represents the base friction, the "viscous" and "turbulent" type coefficients represent the internal friction, and the value is related to the velocity. To determine the friction parameters more accurately, it is necessary to carry out a flume test. Friction parameters are affected by fluid height, velocity, flow rate, and debris flow development (flow path, material composition, accumulation).

After the calibration and analysis of the test parameters from the field test and measurement, the monitoring points $\mathrm{A}, \mathrm{B}$ and $\mathrm{C}$ with an interval of $0.5 \mathrm{~m}$ were taken in the middle of the flow groove bottom to analyze the debris flow deposition height, and 
the friction parameters of RAMMS were corrected by comparing with the field monitored results (Fig. 6(a)). Numerical simulation parameters of the debris flow were determined as follows: dry friction coefficient $\mu=0.07$, and viscous/turbulence coefficient $\xi=1700$.

Table 2: Comparison chart of deposit height of monitoring point

\begin{tabular}{cccc}
\hline Monitoring point & A & B & C \\
\hline Flue test monitor $(\mathrm{m})$ & 0.68 & 0.35 & 0.25 \\
Numerical simulation $(\mathrm{m})$ & 0.73 & 0.37 & 0.21 \\
\hline
\end{tabular}

Tab. 2 suggests that the flow variation trend of monitoring points is almost the same, and the deposition height of the debris flow gradually decreases $(A>B>C)$. In the range of $t=0 \sim 1 \mathrm{~s}$, the debris flow in the released area passes through three monitoring points in sequence, and the sedimentary height of the debris flow at the monitoring point increases sharply. When $t=1 \mathrm{~s}$, the flow of the monitored points $\mathrm{A}, \mathrm{B}$ and $\mathrm{C}$ reaches the maximum value, which are $0.725 \mathrm{~m}, 0.374 \mathrm{~m}$ and $0.209 \mathrm{~m}$ respectively (Fig. 7). Within the range of $t=1 \sim 2 \mathrm{~s}$, the debris flow moves to the downstream of the monitoring point, the debris flow at the monitoring point drops sharply, and debris flow deposition height at the three monitoring points is small. When $t=2 \sim 10 \mathrm{~s}$, the height of debris flow deposition at the monitoring point remains unchanged.

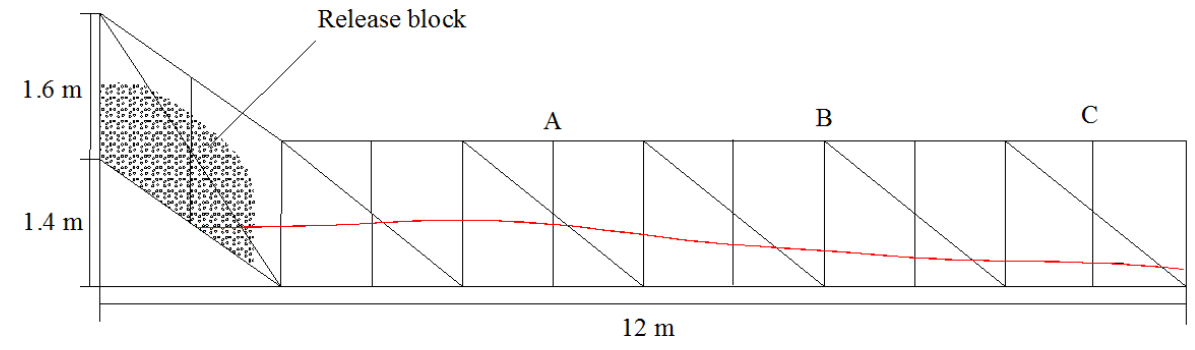

Figure 7: Flume test sketch (red line is a curve of the deposit thickness)

The maximum values of flow change at the monitoring point of the in-situ flume model test are point $\mathrm{A}(0.681)$, point $\mathrm{B}(0.359)$, and point $\mathrm{C}(0.256)$. By comparing the results of the flow change at the monitored points from the numerical simulation and the field test, it is found that the numerical simulation results are slightly smaller than the actual monitored flow results, whereas the flow variation trend and deposition height are almost the same.

\subsection{Calculated parameters}

Based on the field investigation and genesis analysis of the debris flow, the loose accumulation in the debris flow source area near the Huanglong mountain peak was used as the release area for numerical simulation. Using the complex three dimensional digital terrain model generation technology as shown in Fig. 8, the topographic map was first imported into CASS and ARCIS, and then transformed and analyzed to yield the digital elevation information model DEM. The results are shown in Fig. 8, in which the gray "L" shaped area represents the calculated area that contains important topographical information, and the green strip-shaped area represents the release area of the debris flow movement. The release area was created through a new polygon shape-file with the 
compare different Google maps between pro-debris flow and post-debris flow. The calculation results showed that the release zone exhibited a height of $5.4 \mathrm{~m}$ and a volume of about $1.14 \times 10^{5} \mathrm{~m}^{3}$. The motion stopping mechanism of the clastic flow set by RAMMS was based on momentum conservation. When the momentum of all node units was less than $5 \%$ of the maximum value, the motion stops by default [Malet, Laigle, Remaitre et al. (2004)]. According to the experimental and numerical simulation verification parameters of the debris flow in the flow groove test, the simulation parameters of the prototype debris flow model of the debris flow are obtained (Tab. 3 ).

Table 3: Friction parameters and Simulation parameters

\begin{tabular}{|c|c|c|c|c|c|}
\hline \multicolumn{2}{|c|}{ Friction parameters } & \multicolumn{2}{|c|}{$\begin{array}{l}\text { Input parameters of the numerical } \\
\text { model }\end{array}$} & \multicolumn{2}{|l|}{ Numerical results } \\
\hline $\begin{array}{l}\text { Friction } \\
\text { coefficient } \mu\end{array}$ & 0.070 & $\begin{array}{l}\text { Release } \\
\text { depth }\end{array}$ & $5.40 \mathrm{~m}$ & End time of simulation & $14600 \mathrm{~s}$ \\
\hline \multirow[t]{8}{*}{$\begin{array}{l}\text { Viscous } \\
\text { coefficient } \xi\end{array}$} & $\begin{array}{l}1500.00 \\
\mathrm{~m} / \mathrm{s}^{2}\end{array}$ & $\begin{array}{l}\text { Average } \\
\text { slope angle }\end{array}$ & $33.72^{\circ}$ & $\begin{array}{l}\text { Animation dump } \\
\text { interval }\end{array}$ & $5 \mathrm{~s}$ \\
\hline & & Elevation & $1506 \mathrm{~m}$ & Simulation stop reason & $\begin{array}{l}\text { Low flux } \\
\text { equilibrium }\end{array}$ \\
\hline & & $\begin{array}{l}\text { Numerical } \\
\text { solver }\end{array}$ & $\begin{array}{l}\text { second order } \\
\text { accuracy }\end{array}$ & Actual simulation time & $15785.00 \mathrm{~s}$ \\
\hline & & Curvature & 1 & Release volume & $254531 \mathrm{~m}^{3}$ \\
\hline & & \multirow{2}{*}{\multicolumn{2}{|c|}{$\begin{array}{l}\text { Simulation } \\
\text { grid } \\
\text { resolution }\end{array}$}} & Total maximum velocity & $38.3477 \mathrm{~m} / \mathrm{s}$ \\
\hline & & & & $\begin{array}{l}\text { Total maximum deposit } \\
\text { height }\end{array}$ & $12.63 \mathrm{~m}$ \\
\hline & & & & $\begin{array}{l}\text { Total maximum Head } \\
\text { pressure }\end{array}$ & $2573.46 \mathrm{kPa}$ \\
\hline & & & & Number of cells/nodes & $\begin{array}{l}1334514 / \\
1338190\end{array}$ \\
\hline
\end{tabular}

\section{Results}

\subsection{Sediment depth}

The debris flow simulation was performed using the above Voellmy numerical model and calculation conditions. Without considering obstacles, the defined release area includes the loose deposit area at the source area of the debris flow as defined in Fig. 8(a). The calculation topography before the activation of Luzhuang gully debris flow is shown in Fig. 8(b).

At the initial stage of the movement of the debris flow when $t=290 \mathrm{~s}$, the mud-rock flow ditched to Luzhuang central low-lying place together, and quickly flowed the Pingshi temple, as shown in Fig. 9(a). The debris flow moved from upstream to Pingshi temple, generally displaying the streamline distribution. The debris flow deposit distributed largely along the main channel in Lu Zhuang groove, and the maximal sedimentary height in the section was $H_{\max }=8.73 \mathrm{~m}$.

When $t=600 \mathrm{~s}$, after the debris flow moved through Pingshi temple, part of the debris flow moved to Luojia along the gully of the terrain. At this time, the maximum deposition height was $H_{\max }=6.81 \mathrm{~m}$. Compared with the initial stage of debris flow movement, the deposition 
depth decreased with the increase in the deposition range. As shown in Fig. 9(b), the deposition height was slightly higher at the convergence point of the great depression, suggesting that the debris flow deposited thickly in the low-lying area.

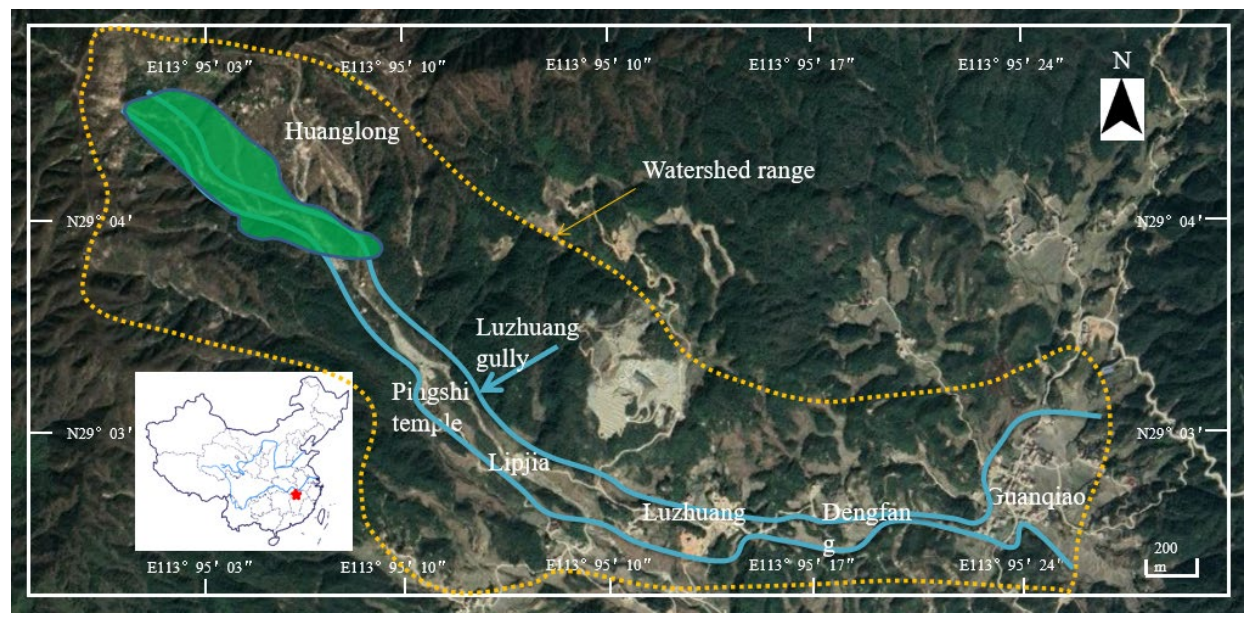

(a)

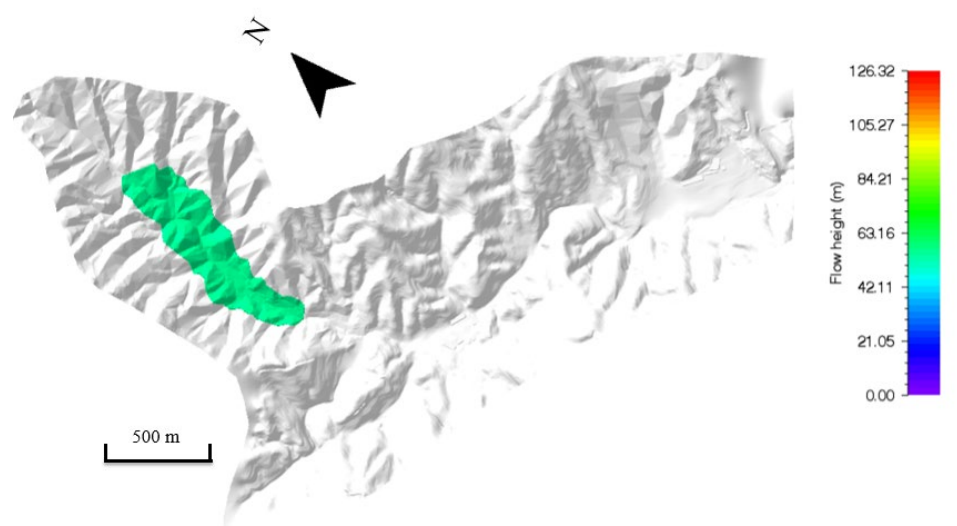

(b)

Figure 8: Google image after the event and position of defined release area (a); Calculation topography before the activation of Luzhuang gully debris flow (b)

When $t=4000 \mathrm{~s}$, the debris flow moved through the U-shaped valley between Luzhuang village and the downstream of Luojia village and reached the gentle position before Luzhuang village. As shown in Fig. 9(c), the movement distance of debris flow increased, the flow area was expanded, and then the sediment depth of debris flow in the area above Luzhuang village gradually decreased, with $H_{\max }=5.45 \mathrm{~m}$. At this time, the debris flow near the village of Luzhuang village increased further, and some houses and farmland were destroyed.

When $t=14600 \mathrm{~s}$, the movement of the debris flow ended and the distribution of the final deposition height is shown in Fig. 9(d). The debris flow was deposited at Guanqiao finally. The total volume of debris flow in the downstream of debris flow was about 
$1.33 \times 10^{5} \mathrm{~m}^{3}$, which is almost consistent with the amount of debris flow movement in the field investigation and test.

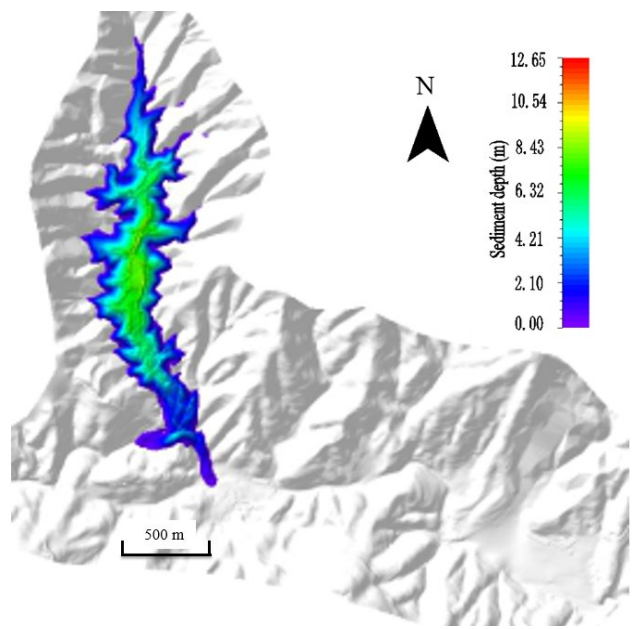

(a) $t=290 \mathrm{~s}$

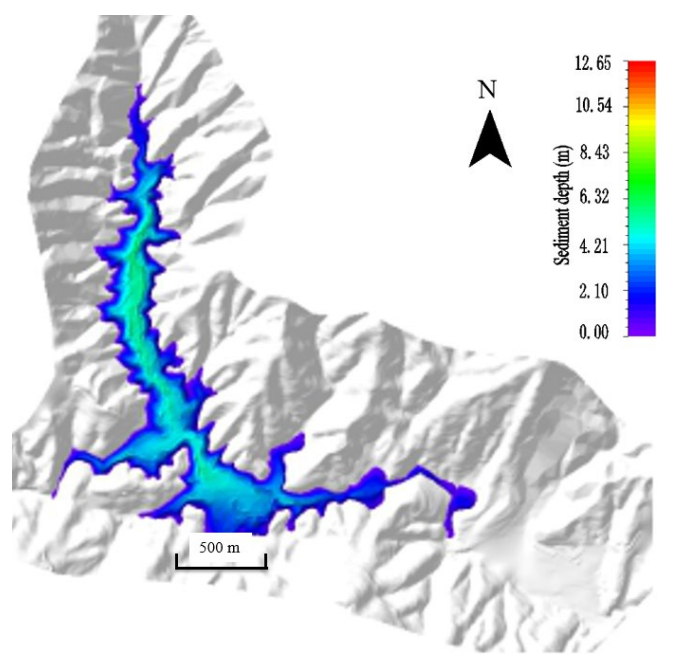

(c) $t=5200 \mathrm{~s}$

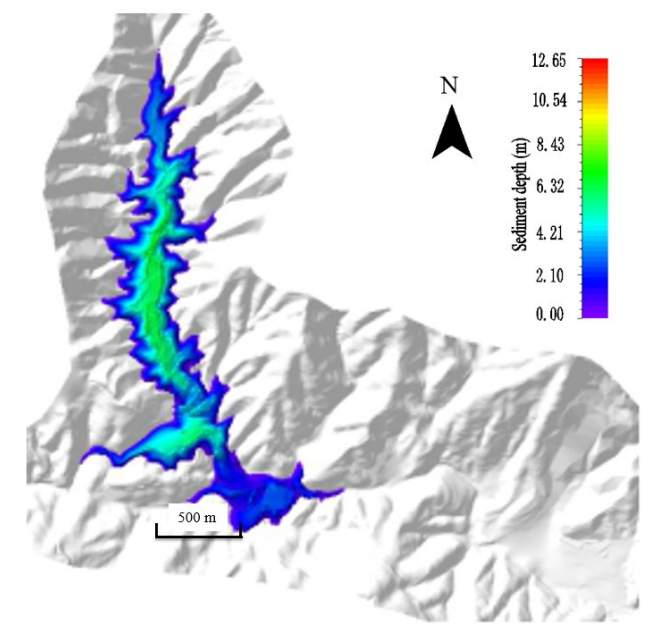

(b) $t=600 \mathrm{~s}$

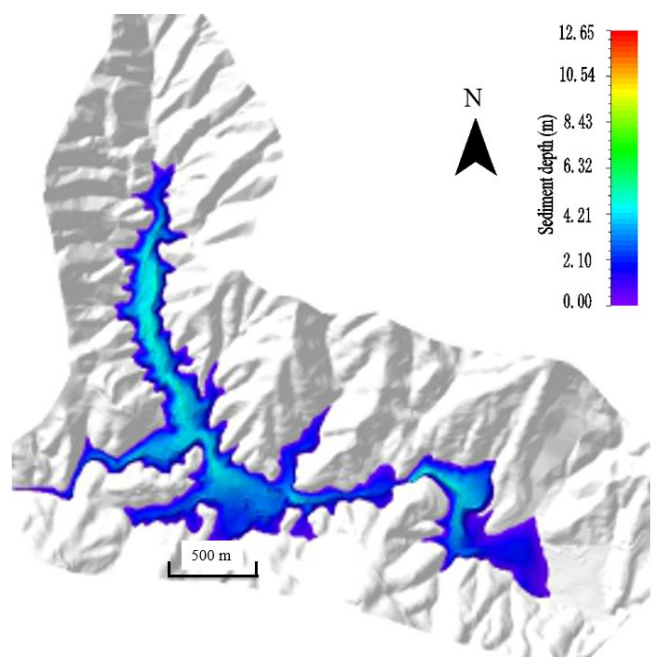

(d) $t=14600 \mathrm{~s}$

Figure 9: Simulation of sediment depth of the Luzhuang gully debris flow

With the increase in time of the debris flow, the upstream debris flow slid down at a high speed, and the deposition depth of the upstream debris flow decreased over time. Subsequently, the debris flow gradually moved to the middle and lower reaches, and the deposition depth of the debris flow in the middle and lower reaches continuously increased. Finally, the debris flow was primarily in the downstream area, and the results of numerical simulation and model tests were almost consistent. 


\subsection{Flow velocity}

Fig. 10(a) shows that in the initial stage of debris flow, the velocity of debris flow increases greatly over time, that is, when $t=290 \mathrm{~s}$, the velocity of debris flow is very large, the velocity tends to be large in the Luojia village and small in the up-gully, and the velocity of debris flow at the intersection with Da'ao gully is the largest, $V_{\max }=28.47 \mathrm{~m} / \mathrm{s}$.

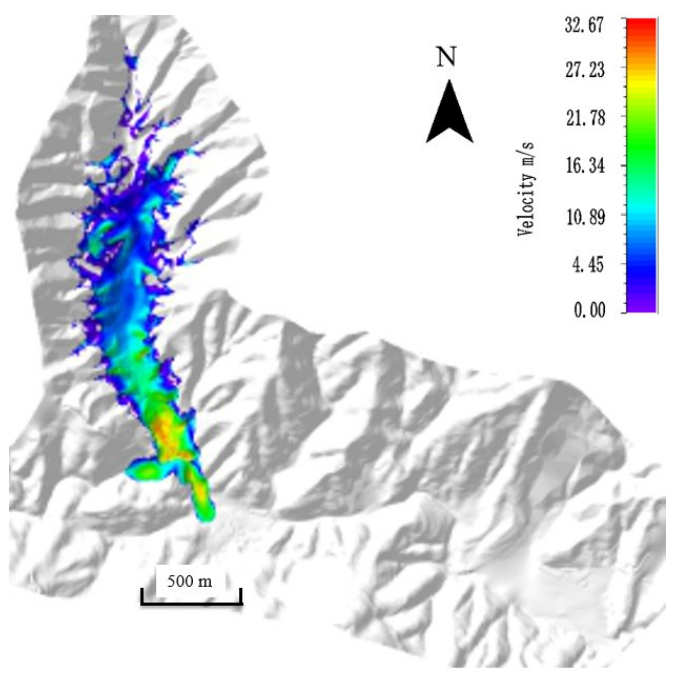

(a) $t=290 \mathrm{~s}$

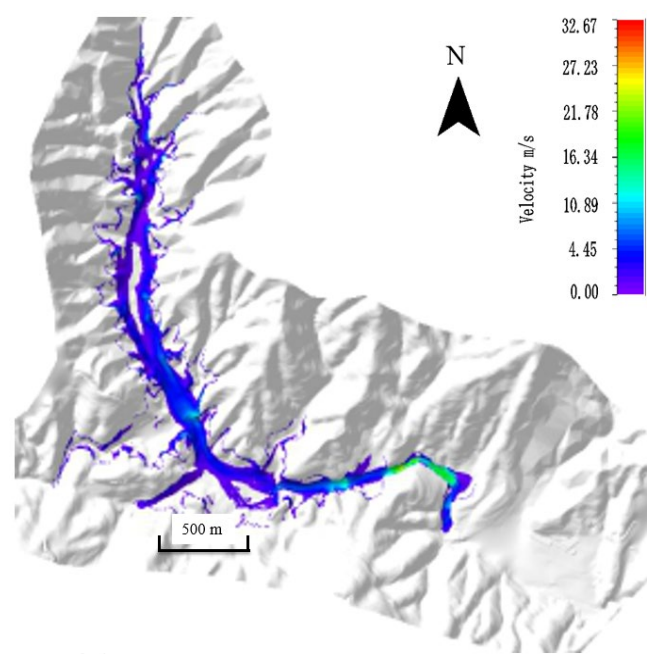

(c) $t=5200 \mathrm{~s}$

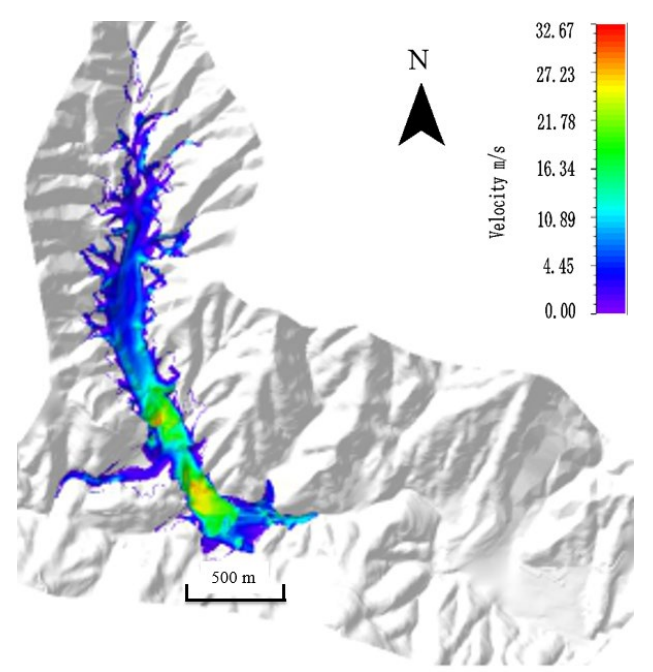

(b) $t=600 \mathrm{~s}$

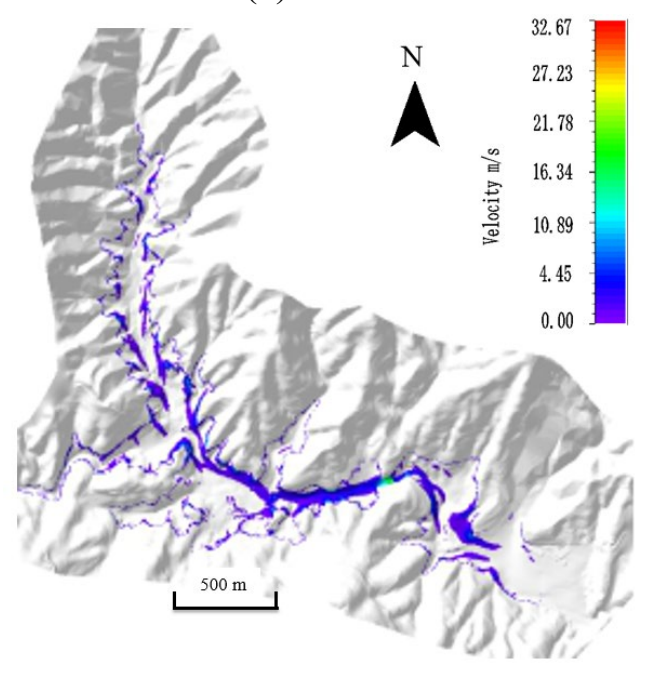

(d) $t=14600 \mathrm{~s}$

Figure 10: Simulation result of the velocity in Luzhuang gully debris flow

Fig. 10(b) shows that when $t=600 \mathrm{~s}$, the flow velocity of the debris flow from Luojia village to Luzhuang village remains very high, and the maximum velocity in Luzhuang village is $27.07 \mathrm{~m} / \mathrm{s}$. The velocity is laid out in a long strip along the bottom of the hill.

In Fig. $10(\mathrm{c})$, when $t=5200 \mathrm{~s}$, the debris flow moves from Luzhuang village to the 
topography junction at the upstream of Dengfang village. At this time, the flow velocity of the debris flow decreases, and the upstream movement of the debris flow is nearly stopped. However, the velocity of the debris flow remains high in the front part where the debris flow evolves to the downstream of Dengqiao, and the maximum at Dengfang village is $26.13 \mathrm{~m} / \mathrm{s}$, indicating that the debris flow is still advancing to the downstream at a high speed.

Fig. 10(d) shows that when $t=14,600 \mathrm{~s}$, the movement of the entire debris flow almost stops, and at this time, except for the local topographic junction at the downstream of the main ditch, the velocity of the debris flow is very high, and Vmax at this stage is 21.07 $\mathrm{m} / \mathrm{s}$. The results indicate that the formation of this kind of high-speed debris flow is mainly caused by the effects of multiple facts including the extreme rainfall, steep terrain, large catchment area, narrow channel and other factors.

According to the above analysis, at the initial stage of movement ( $t \leq 290 \mathrm{~s})$, the debris flow is very fast and flows down the channel. In this stage, the flow rate of debris flow is very fast in the process of advancing downstream, reflecting the conversion of potential energy to kinetic energy in the process of movement, which causes the formation of a huge impact force of debris flow. In the middle and late period of the movement $(5,200$ $\mathrm{s} \leq t \leq 14,600 \mathrm{~s}$ ), the flow velocity of local debris flow is affected by the confluence of branch gullies, and the movement speed is still very high, whereas the terrain slows down, and the overall flow velocity decreases. This reflects that at this stage, the kinetic energy of the debris flow is exhausted, and the movement gradually stops with the continuous decrease in the velocity of the debris flow.

\subsection{The sensitivity analysis at the key section}

Monitoring the sections and sensitive points were arranged in the middle and lower reaches of the debris flow area. The location of the monitored section in the numerical simulation was almost consistent with the physical model. To study the key section sensitivity, five profiles were set in the debris flow simulation: \#1 at Pingshi temple, \#2 at Luojia village, \#3 in Luzhuang village, \#4 at the last topographic junction position upstream of Dengfang, and \#5 close to the upstream of Guanqiao village (Fig. 11).
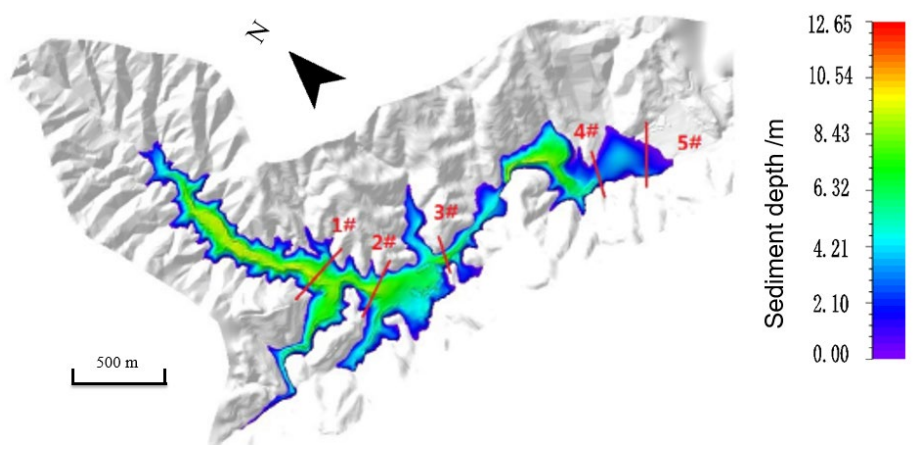

Figure 11: Key section of the debris flow 


\subsubsection{Section \#1: Pingshi temple}

Fig. 12(a) shows the variation of the linear flow in Section 1\#. The green line shown in the figure represents the topographic contour of the Pingshi temple in section 1\#, and the red line in Fig. 12(a) represents the flow rate change in section 1 in the process the debris flow. From Fig. 12(a), the flow rate of the debris flow in this section is about $3236.8 \mathrm{~m} / \mathrm{s}$ (multiplied by 50) added to the track profile (altitude, scale on the right side). The gray area is the variation of the final deposition height of this section. The maximum height of the debris flow deposition in Section 1\# is $4.11 \mathrm{~m}$. The variation of the deposition height and flow rate of the debris flow in this cross-section shows that there are many gullies in the middle and the areas with higher terrain on both sides are low.

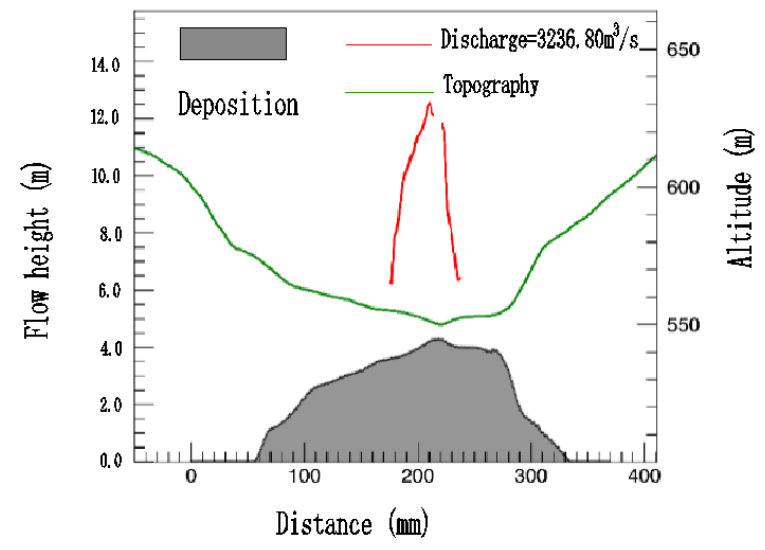

(a)

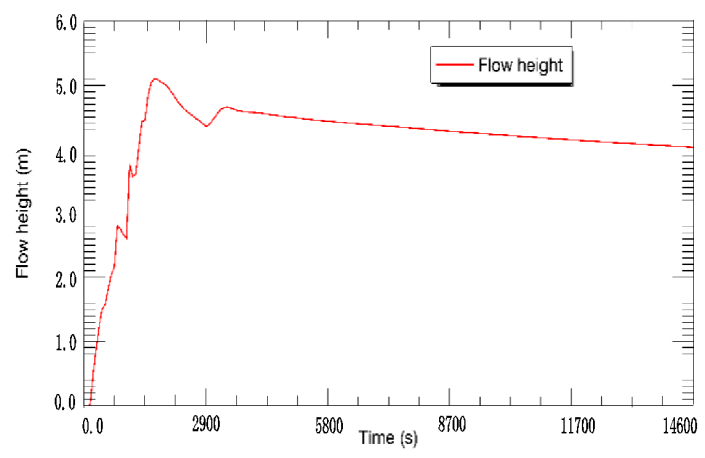

(b)

Figure 12: Profile of $1 \#$ section (a) and it sediment thickness in middle point (b)

Fig. 12(b) shows the variation of debris flow deposition height at the middle point of Section 1. At the initial stage of the debris flow movement, the height of debris flow deposition at the middle point of the measured section in \# 1 (the red line) increases rapidly and reaches the maximum at around $t=60 \mathrm{~s}$. At the moment of $t=1,500 \mathrm{~s}$, the debris flow is primarily deposited at the location of Pingshi temple groove. During the period of $t=1,500 \sim 14,600 \mathrm{~s}$, the deposition height of the debris flow at the Pingshi temple gradually decreases. The debris flow in this area evolves slowly, and the debris flow is 
gradually deposited in this area. Finally, the maximum deposition height at the Pingshi temple gully mouth of Section 1 is $4.1 \mathrm{~m}$.

\subsubsection{Section \#2: Luojia village}

As can be seen from Fig. 13(a), the topography of the upper reaches of the Luojia village varies greatly. The lowest elevation of this catchment area is about $531 \mathrm{~m}$. The flow change trend of the debris flow in this section is roughly the same as that in Section 1. The maximum flow rate at Section $2 \#$ is $4,841.3 \mathrm{~m}^{3} / \mathrm{s}$, and the maximum deposition height of debris flow in the upstream Luojia village is $4.08 \mathrm{~m}$.

Fig. 13(b) suggests that, according to the variation of the line flow diagram at the midpoint of the section, there is no flow change at this point during the period when $t<290 \mathrm{~s}$, suggesting that the debris flow moves rapidly from the Pingshi temple to the Luojia village when $t=290 \mathrm{~s}$. During the period from $t=290 \mathrm{~s}$ to $1,500 \mathrm{~s}$, the deposition height of the debris flow increases to $1.8 \mathrm{~m}$, and then decreases slightly (the red line). During the period of $t=1,500 \mathrm{~s} \sim 3,000 \mathrm{~s}$, the deposition height at Section 2 increases rapidly and reaches the maximum value around $t=3,000 \mathrm{~s}$ of $H_{\max }=4.08 \mathrm{~m}$, indicating that the debris flow primarily flows through the upstream of the Luojia village at this moment. When $t=3,000 \mathrm{~s} \sim 14,600 \mathrm{~s}$, the sedimentary height of the debris flow in this area gradually decreases from $4.08 \mathrm{~m}$ to $4.0 \mathrm{~m}$. When $t>3,000 \mathrm{~s}$, the debris flow begins to move up to the downstream of the village, and the remaining debris flow in this area begin to deposit, at a slow flow rate. Some houses in Luojia village were submerged.

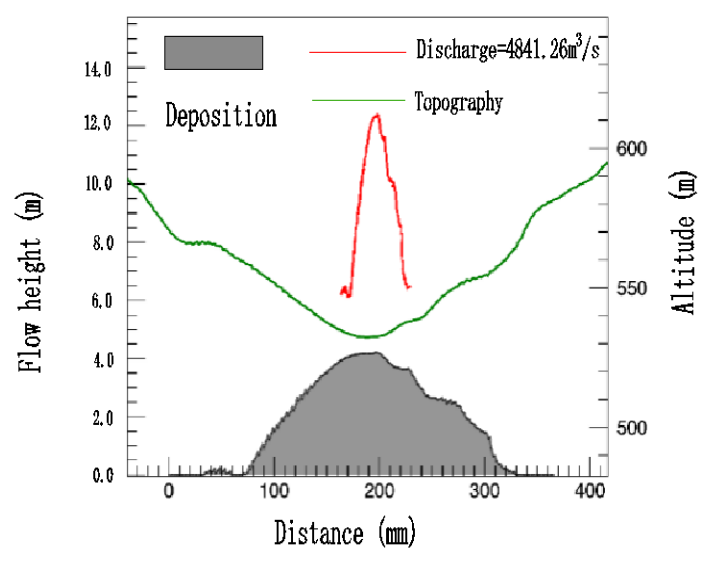

(a) 


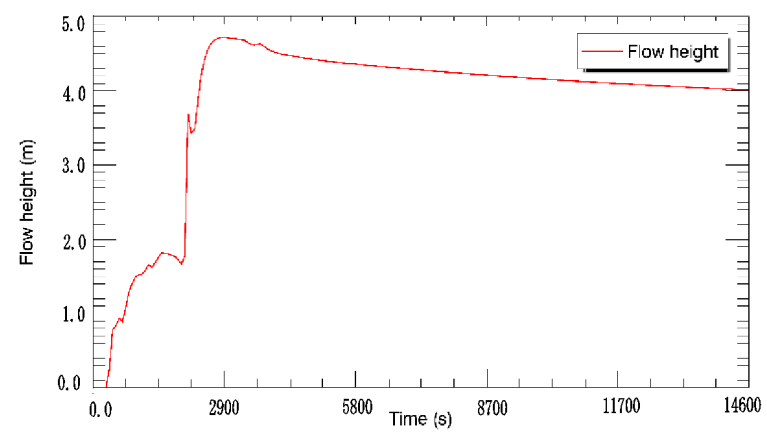

(b)

Figure 13: Profile of 2\# section (a) and its sediment thickness in middle point (b)

\subsubsection{Section \#3: Luzhuang village}

Fig. 14(a) shows that the flow rate of the debris flow in this section is $3,061.1 \mathrm{~m}^{3} / \mathrm{s}$ (red line), and the final deposition height was $3.86 \mathrm{~m}$ (green line). The red line in Fig. 14(b) suggests that at $t=600 \mathrm{~s}$, the debris flow reaches the downstream of the Luzhuang village, and it takes $600 \mathrm{~s}$ to reach the downstream from the upstream of the Luzhuang village. When $t=600 \mathrm{~s} \sim 1,600 \mathrm{~s}$, the debris flow flows rapidly through Section \#3 topographic junction in this period and continues to evolve downstream. The height of the debris flow deposition on the section increases rapidly from $0 \mathrm{~m}$ to $3.7 \mathrm{~m}$. When $t=1,600 \mathrm{~s} \sim 4,060 \mathrm{~s}$, which reflects that the debris flow passes through the topographic closure of this area and flows rapidly to the downstream of the reservoir area, the debris flow with less kinetic energy remaining starts to deposit. When $t=600 \mathrm{~s} \sim 4,060 \mathrm{~s}$, the deposition height of debris flow at this section increases slightly from $3.7 \mathrm{~m}$ to $3.86 \mathrm{~m}$, which also reflects that the topographic closure hinders the evolution of debris flow. At $t=4,060 \mathrm{~s} \sim 14,600 \mathrm{~s}$, the height of debris flow deposition at the middle point of this section drops from $3.86 \mathrm{~m}$ to $3.7 \mathrm{~m}$.

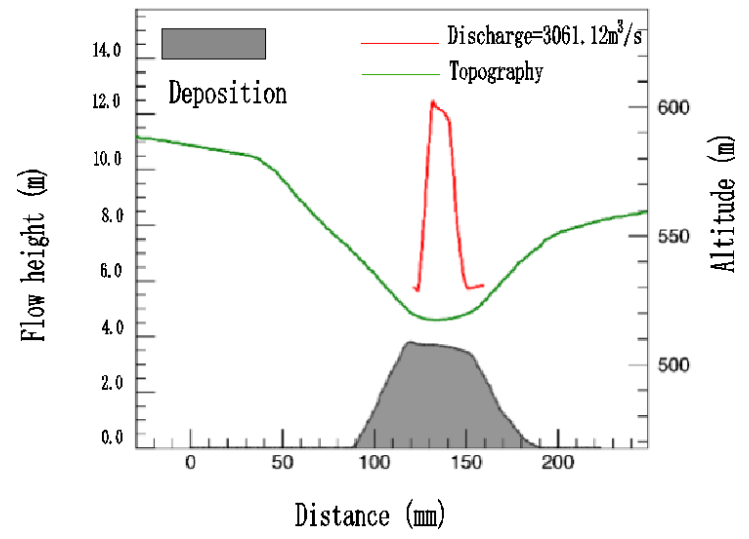

(a) 


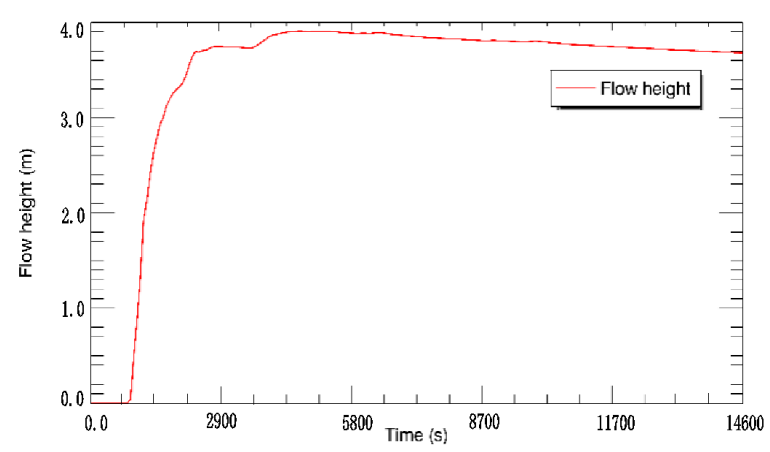

(b)

Figure 14: Profile of $3 \#$ section (a) and sediment thickness in middle point (b)

\subsubsection{Section \#4: Dengfang village}

Compared with Section 3, Section 4 is relatively flat. From the red line in Fig. 15(a), the maximum deposition height of the debris flow is $1.53 \mathrm{~m}$, and the flow rate of debris flow in Section 4 is $1,516.11 \mathrm{~m}^{3} / \mathrm{s}$ at the end of the movement. When the time was about 5,200 $\mathrm{s}$, the debris flow moved to the last topographic junction in the upstream of Dengfang village. At $t=5,200 \mathrm{~s} \sim 5,700 \mathrm{~s}$, the deposition height of the debris flow in this section increase rapidly from $0 \mathrm{~m}$ to about $0.45 \mathrm{~m}$, which indicates that the debris flow starts to flow through the upstream of Dengfang village during this period. When $t=5,700$ $\mathrm{s} \sim 14,600 \mathrm{~s}$, the height of debris flow deposition in section 4 increases from $0.45 \mathrm{~m}$ to $1.59 \mathrm{~m}$ at a constant rate. It indicates that the sediment thickness continues to increase due to the sand-carrying effect of the upstream debris flow. This reflects the mud-rock flow from the reservoir to be in the process of the upstream village most of the kinetic energy is dissipation. Most of the debris flow deposits in the process of evolution of debris flow downstream, the movement of debris flow at the upstream village is coming to an end (Fig. 14).

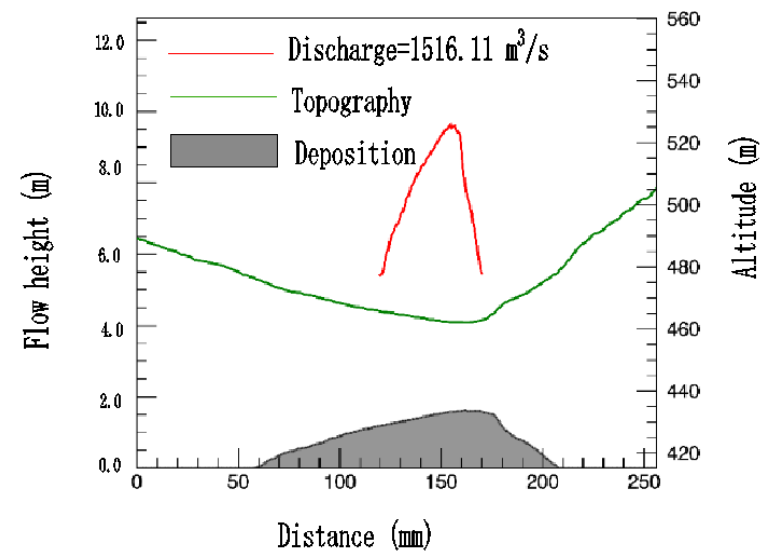

(a) 


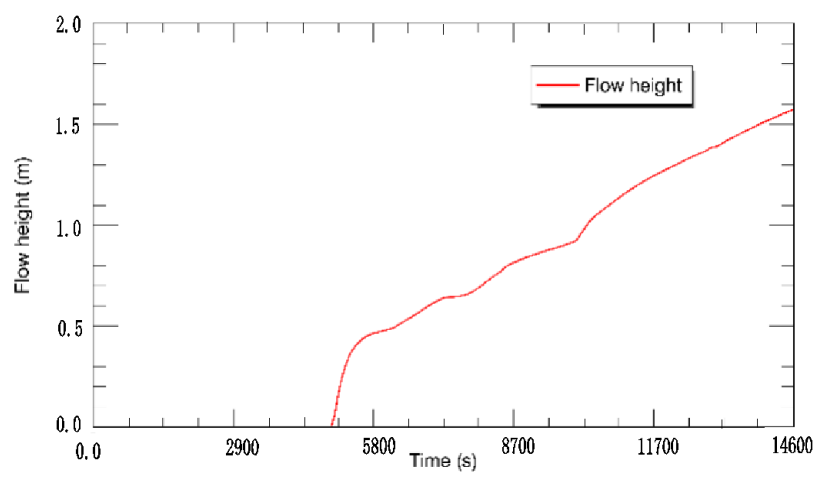

(b)

Figure 15: Profile of 4\# section (a) and its sediment thickness in middle point (b)

\subsubsection{Section \#5: Guanqiao village}

When the debris flow reaches the upstream area of Guanqiao village, the movement of the debris flow almost ends. At the end of the debris flow movement, the maximum flow rate of the debris flow in this section was $329 \mathrm{~m}^{3} / \mathrm{s}$ (red line), and the maximum deposition height was $1.33 \mathrm{~m}$ (green line). The debris flow moved to the upstream of the Guanqiao village at $t=8,100 \mathrm{~s}$. Subsequently, when $t=8,100 \mathrm{~s} \sim 14,600 \mathrm{~s}$, the deposition height of the debris flow in this section was elevated from $0 \mathrm{~m}$ to $1.33 \mathrm{~m}$.

Due to the sand-carrying effect of mud-rock flow in the upstream, mud-rock mixture keeps accumulating in the downstream, and the thickness of mud-rock flow accumulation in section \#4 and section \#5 still increases linearly (Figs. 15 and 16). The velocities obtained from the reported simulation are similar to the other data obtained from field investigation and theoretical calculation in debris mouth [Gan, Yuan and Li (2017)].

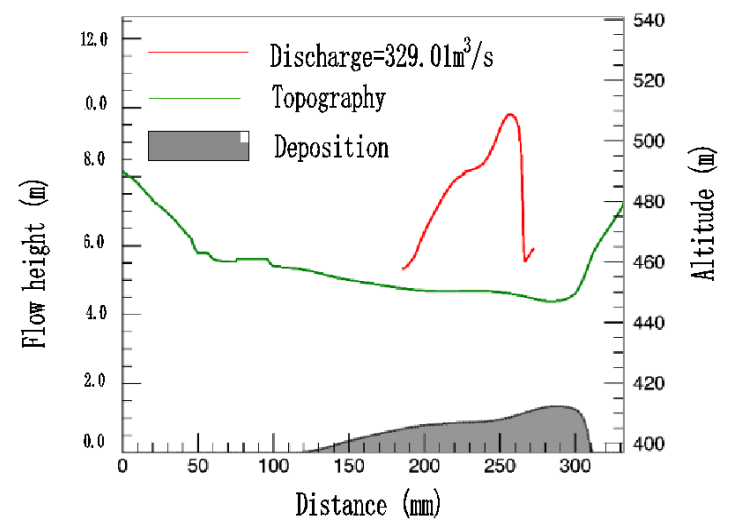

(a) 


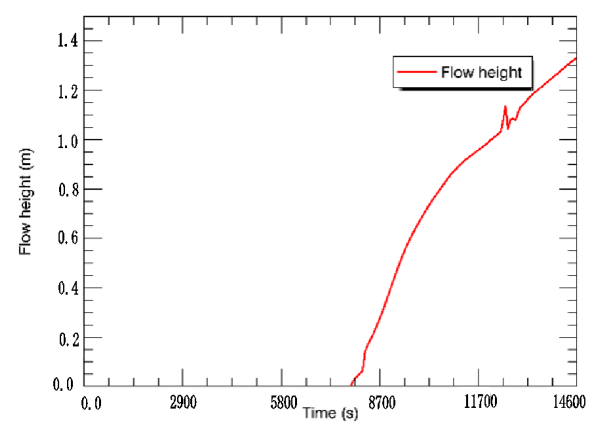

(b)

Figure 16: Profile of \#5 section (a) and it is sediment thickness in middle point (b)

\section{Discussion}

Field debris flow investigation was performed on August 15, 2012, and the movement speed, accumulation thickness and migration distance of the debris flow were identified. According to the investigation results (The duration of the mudslide is based on the survey of residents and the monitoring of the nearby hydrological station), on June 10, 2011, Luzhuangou area was hit by heavy rain, which lasted for 4.1 hours and the maximum deposition thickness reached $4.1 \mathrm{~m}$, and the debris flow outflowed more than 100,000 cubic meters. Besides, field tests were performed on the particle composition of the debris flow. The field investigation, in-situ measurements, laboratory experiment data, and RAMMS numerical simulation data were used for comparative analysis, and the test results were extended to the prototype project according to the similarity criteria, in an attempt to analyze the potential disaster range of the next evolution of debris flow. In the numerical simulation, RAMMS, a software for dynamic analysis of debris flow, is used to perform numerical calculation and image display on a computer workstation, in an attempt to quantitatively describe the numerical solution of debris flow in the computational region in time and space. Dynamic simulation of the evolution process of the debris flow in a complex terrain was conducted, and comparative analysis was conducted with the results of the model test to determine the scope of potential risk area of the debris flow and the impact of specific disasters (Tab. 4).

\subsection{Key parameter selection}

RAMMS debris flow dynamic analysis software was based on the Voellmy flow friction theory. It was assumed that the debris flow is a one-way model, and all debris flow materials were taken as a whole, so solid phase and liquid phase materials could not be separated. Friction resistance was controlled by the dry friction parameter $(\mu)$ and viscous/turbulent flow type parameter $(\xi)$. Therefore, the biggest difficulty in simulating tailings pond dam break with RAMMS was that the tailings clastic flow in the process of overtopping dam break had very complex composition, and the selection of friction parameters has obvious effects on the result. Through necessary field measurement, combining with a flow velocity change of debris flow in the flume test and considering flow path and deposition distribution of debris flow, the friction parameters of RAMMS 
numerical simulation were finally determined as $\mu=0.07$ and $\xi=1500$, respectively. The main reason for the short predicted time is that the parameters of the model are selected in the single-phase flow state, while the actual dry friction coefficient and viscosity coefficient of the flow is quite complex, resulting in a large difference in different of the numerical simulation.

\subsection{Debris flow movement process}

The model was capable of reflecting the details of the debris flow movement process in the process of breaking, with debris flow upstream of rainwater gathering Lu Zhuang groove on both sides of the upstream and debris piled up. The first is the loose accumulation of slope surface eroded by rainfall, and then forms collapse and slide, and accumulates in the channel to form the weir plug body, leading to the increase of potential energy. With the continuous rainfall and the collection of the branches of the rainwater, dam burst, forming a large debris flow. According to Voellmy theory, RAMMS numerical simulation takes debris flow as a one-way average mixture and reflects flow characteristics of tailings debris flow through friction parameters. However, friction parameters are constant in space and time, which could not truly reflect that debris flow particle gradation, friction coefficient, shear strength and other realities exhibited spatial-temporal variability.

Table 4: Results between the field survey/measurement and numerical simulation

\begin{tabular}{|c|c|c|}
\hline Main parameter & Field survey method/Measurements & Numerical simulation \\
\hline Topography & Topographic and satellite maps & DEM \\
\hline Lithology & Drifts, pebbles and debris flows & Clastic particles \\
\hline Calculated parameters & $\mu=0.07, \zeta=1500$ & $\mu=0.07, \zeta=1500$ \\
\hline Failure process & $\begin{array}{l}\text { Rainstorm - landslide - confluence erosion - old } \\
\text { debris flow - gully accumulation }\end{array}$ & $\begin{array}{l}\text { Debris flow collapse - low-lying } \\
\text { convergence - accumulation flow }\end{array}$ \\
\hline $\begin{array}{l}\text { Debris flow } \\
\text { inducement }\end{array}$ & Rainstorm catchment -rock slide & Define the release zone properties \\
\hline $\begin{array}{l}\text { Evolution of debris } \\
\text { flow }\end{array}$ & $\begin{array}{l}\text { Most farmland and houses in Luojia and } \\
\text { Luzhuang villages were flooded }\end{array}$ & $\begin{array}{l}\text { Most farmland and houses in Luojia } \\
\text { and Luzhuang villages were flooded }\end{array}$ \\
\hline Outfall & $10.08 \times 10^{4} \mathrm{~m}^{3}$ & $1.33 \times 10^{5} \mathrm{~m}^{3}$ \\
\hline Sediment & $\begin{array}{l}\text { Luojia-Guanqiao ditch and its sides, some } \\
\text { farmland was flooded }\end{array}$ & $\begin{array}{l}\text { Luojia to Guanqiao ditch and its two } \\
\text { sides }\end{array}$ \\
\hline Time & 4.1 hours & 4.26 hours \\
\hline $\begin{array}{l}\text { Sediment height at } \\
\text { section \#1 }\end{array}$ & $4.1 \mathrm{~m}$ & $4.11 \mathrm{~m}$ \\
\hline $\begin{array}{l}\text { Sediment height at } \\
\text { section } \# 2\end{array}$ & $1.9 \mathrm{~m}$ & $4.08 \mathrm{~m}$ \\
\hline $\begin{array}{l}\text { Sediment height at } \\
\text { section } \# 3\end{array}$ & $1.4 \mathrm{~m}$ & $3.86 \mathrm{~m}$ \\
\hline $\begin{array}{l}\text { Sediment height at } \\
\text { section } \# 4\end{array}$ & $1.4 \mathrm{~m}$ & $1.53 \mathrm{~m}$ \\
\hline $\begin{array}{l}\text { Sediment height at } \\
\text { section } \# 5\end{array}$ & $1.6 \mathrm{~m}$ & $1.28 \mathrm{~m}$ \\
\hline
\end{tabular}


However, RAMMS could reflect the situation of debris flow aggregation and downward movement and accumulation towards low-lying areas in the middle and lower reaches from a macro perspective and elucidate the complete evolution process of debris flow.

\subsection{Debris flow evolution}

The two analysis results of field investigation and numerical simulation show that the evolution of the downstream was almost the same, and the total deposition of debris flow was almost the same, $V \approx 1.30 \times 10^{5} \mathrm{~m}^{3}$. The model test and the numerical simulation analysis showed that the debris flow eventually submerged to Guanqiao, and only a few houses with higher elevation ( $531 \mathrm{~m}$ or more) were not affected by the debris flow. Numerical simulation analysis showed that the debris flow eventually evolved to the upstream of Guanqiao village, and only a small number of houses upstream were affected by the debris flow.

\subsection{Comparison of debris flow deposition}

A monitoring section was set at a key position in the middle and lower reaches of debris flow. The final deposition height, flow rate change process over time and flow rate at the final section of each monitoring section were compared through field survey, actual measurement and numerical simulation analysis. The comparative analysis of field investigation and numerical simulation results as shown in Tab. 3 revealed that the debris flow deposition heights at Sections 1, 4, and 5 were almost the same, and there was a significant difference in the debris flow deposition heights between the area of Luojia village, Luzhuang and Dengfang (Sections 2, 3), probably due to the difference in debris flow particle size distribution and friction coefficient setting. The comparison of the results of RAMMS numerical simulation with the in-situ investigation suggested that the numerical simulation could help analyze the evolution of debris flow and its disastercausing effects by properly adjusting the related parameters.

\section{Conclusions}

The Voellmy fluid motion model complies with the momentum conservation law, and can better simulate the migration and accumulation process of debris flow runout, eventually obtain the failure range and the travel distance of debris flow disaster. But there is some limitation of the proposed numerical approach. The time length of the debris flows event is 4.1 hours, while in the numerical simulation it lasts only 4.06 hours, showing a small discrepancy with effective time length between simulation and field investigation. Therefore, as long as the correct dry friction coefficient and viscosity coefficient are adopted, the numerical simulation method can be used to verify the debris flow duration in the field investigation.

The dry friction coefficient $\mu$ and the viscous coefficient $\xi$ allows modeling the movement behavior of the single-phase flow. The back analysis of the in-situ flume test shows that the two key parameters ( $\mu$ and $\xi$ ) to follow the analytical solution. Without further validation, the parameter calibration cannot be automatically employed for prediction purposed of future debris flow events, because of the friction coefficient has a direct influence on the evolution process of debris flow. When the flow is about to stop, the dry friction 
coefficient $\mu$ is a dominant parameter; conversely, when the velocity is quick, the viscous coefficient $\xi$ is a dominant parameter is in the Voellmy model. Numerical simulation results of different locations of debris flow in Luzhuang gully show that the value of Voellmy model parameters will significantly affect the simulation results. As the model parameters are not easy to be obtained through field experiments, a reasonable method is to conduct numerical simulation and back analysis of the flume test to obtain the value of Voellmy model parameters as the simulation parameters of debris flow.

Acknowledgement: This research was partially supported by the Open fund projects of JiangXi Engineering Research Center of Water Engineering Safety and Resources Efficient Utilization(OF201603), Jiangxi Provincial Key Scientific Research Plan (Nos. 20161BBG70051, 20177BBG70046), National Natural Science Foundation of China (Nos. 41641023, 51869012), Jiangxi Provincial Department of Education Science and Technology Research Project Project (No. GJJ151124). We thank Professor Bin Xu and Changtai Luo to assist the flume test. The visiting fellowship and support from Western Sydney University are also acknowledged.

\section{References}

Azam, M. F.; Wagnon, P.; Berthier, E. (2018): Review of the status and mass changes of Himalayan-Karakoram glaciers. Journal of Glaciology, vol. 64, no. 243, pp. 61-74.

Bertolo, P.; Wieczorek, G. F. (2005): Calibration of numerical models for small debris flows in Yosemite Valley, California, USA. Natural Hazards and Earth System Science, vol. 5, no. 6, pp. 993-1001.

Bartelt, P.; Salm, B.; Gruber U. (1999): Calculating dense-snow avalanche runout using a Voellmy-fluid model with active/passive longitudinal straining. Journal of Glaciology, vol. 45, no. 150, pp. 242-254.

Bezak, N.; Sodnik, J.; Mikos, M. (2019): Impact of a random sequence of debris flows on torrential fan formation. Geosciences, vol. 9, no. 2, pp. 1-14.

Berger, C.; Christen, M.; Speerli, J.; Lauber, G.; Ulrich, M. et al. (2016): A comparison of physical and computer-based debris flow modelling of a deflection structure at Illgraben, Switzerland. In: G. Koboltschnig (Ed.), 13th congress INTERPRAEVENT 2016. 30 May to 2 June 2016. Lucerne, Switzerland. Conference proceedings "Living with natural risks", pp. 212-220.

Baum, R. L.; Godt, J. W. (2010): Early warning of rainfall-induced shallow landslide and debris flow in the USE. Landslides, vol. 7, no. 3, pp. 259-272.

Cannon, S. H.; Kirkham, R. M.; Parise, M. (2001): Wildfire-related debris-flow initiation processes, Strom King Mountain, Colorado. Geomorphology, vol. 39, no. 34, pp. 171-188.

Chen, L.; Zong, S. C.; Li, X. L. (2017): Simulation of landslide/debris flow runout process in Ailaoshan using Voellmy model. South to North Water Transfers and Water Science \& Technology, vol. 15, no. 3, pp. 113-119. 
Chen, N. S.; Zhou, W.; Yang, C. L. (2010): The processes and mechanism of failure and debris flow initiation for gravel soil with different clay content. Geomorphology, vol. 121, no. 3, pp. 222-230.

Christen, M.; Kowalski, J.; Bartelt, P. (2010): RAMMS: Numerical simulation of dense snow avalanches in three-dimensional terrain. Cold Regions Science and Technology, vol, 63, no. 1-2, pp. 1-14.

Cui, Y. F.; Zhou, X. J.; Guo, C. X. (2017): Experimental study on the moving characteristics of fine grains in wide grading unconsolidated soil under heavy rainfall. Journal of Mountain Science, vol. 14, no. 3, pp. 417-431.

Dai, F. C.; Lee, C. F.; Wang, S. J. (1999): Analysis of rainstorm-induced slidedebris flows on natural terrain of Lantau Island, Hong Kong. Engineering Geology, vol. 51, no. 4, pp. 279-290.

Domnik, B.; Pudasaini, S. P.; Katzenbach, R.; Miller, S. (2017). Coupling of full two-dimensional and depth-averaged models for granular flows. Journal of NonNewtonian Fluid Mechanics, vol. 201, pp. 56-68.

Dumbser, M.; Toro, E. F. (2011): A simple extension of the Osher Riemann solver to not-conservative hyperbolic systems. Journal of Scientific Computing, vol. 48, no. 1-3, pp. 1-3.

Fan, L. F.; Lehmann, P.; McArdell, P.; Or, D. (2017): Linking rainfall-induced landslides with debris flows runout patterns towards catchment scale hazard assessment. Geomorphology, vol. 280, no. 1, pp. 1-15.

Frank, F.; McArdell, B. W.; Huggel, C; Vieli, A. (2015): The importance of entrainment and bulking on debris flow runout modeling: examples from the Swiss Alps. Natural Hazards and Earth System Science, vol. 15, no. 11, pp. 2569-2583.

Gan, J. J.; Yuan, L. K.; Li, M. (2017): Formation mechanism and dynamic characteristics of rainstorm-induced debris flow in Poyang lake valley of Jiangxi province. Journal of Catastrophology, vol. 32, no. 2, pp. 154-158.

Guan, F. J.; Shen, W. Z.; Zhuang, Z. F. (2018): Analysis, research and trend forecast of national geological disaster prevention and control. Chinese Journal of Geological Hazard and Control, vol. 29, no. 1, pp. 1-2.

Han, Z.; Chen, G. Q.; Li, Y. G.; Tang, C.; Xu, L. et al. (2015b): Numerical simulation of debris-flow behavior incorporating a dynamic method for estimating the entrainment. Engineering Geology, vol. 190, pp. 52-64.

Han, Z.; Su, B.; Li, Y. G.; Wang, W.; Wang, W. D. et al. (2019): Numerical simulation of debris-flow behavior based on the SPH method incorporating the Herschelbulkley-Papanastasiou rheology model. Engineering Geology, vol. 255, pp. 26-36.

Hassan, M. A.; Hogan, D. L.; Bird, S. A. (2005): Spatial and temporal dynamics of wood in headwater streams of the Pacific Northwest. Journal of the American Water Resources Association, vol. 41, no. 4, pp. 899-919.

Harris, C.; Arenson, L. U.; Christiansen, H. H. (2009): Permafrost and climate in Europe: Monitoring and modeling thermal, geomorphological and geotechnical responses. Earth-Science Reviews, vol. 92, no. 3-4. pp. 117-171. 
Hu, H.; Lei, T.; Hu, J.; Zhang, S. L.; Kavan, P. (2018): Disaster-mitigating and general innovative responses to climate disasters: evidence from modern and historical China. International Journal of Disaster Risk Reduction, vol. 18, pp. 664-673.

Hungr, O. (1995): A model for the runout analysis of rapid flow slides, debris flows, and avalanches. Canadian Geotechnical Journal, vol. 32, no. 4, pp. 610-623.

Hungr, O.; Leroueil, S.; Picarelli, L. (2014): The Varnes classification of landslide types, an update. Landslide, vol. 11, no. 2, pp. 167-194.

Iverson, R. M. (1997): The physics of debris flows. Reviews of geophysics, vol. 35, no. 3, pp. 245-296.

Jakob, M.; Hungr, O. (2005): Debris-Flow Hazards and Related Phenomena. Praxis Publishing, Chichester, UK.

Kang, C.; Chan, D. (2018): Numerical simulation of 2D granular flow entrainment using DEM. Granular Matter, vol. 20, no. 1, pp. 12-30.

Kocyigit, Ö.; Gürer, İ. (2007): Effect of the Voellmy coefficients on determining run-out distance: a case study at uzungöl, Turkey. Gazi University Journal of Science, vol. 20, no. 3, pp. 79-85.

Konzuk, J. S.; Kueper, B. H. (2004): Evaluation of cubic law based models describing single-phase flow through a rough-walled fracture. Water Research, vol. 40, no. 2, pp. 1-17.

Laura, M. S.; David, J. P.; Antonino, C.; Foti, E. (2017): A combined triggeringpropagation modeling approach for the assessment of rainfall induced debris flow susceptibility. Journal of Hydrology, vol. 550, no. 7, pp. 130-143.

Liu, W.; He, S. M.; Ouyang, C. J. (2017): Two-dimensional dynamics simulation of two-phase debris flow. ACTA Geologica Sinica (English Edition), vol. 91, no. 5, pp. 1873-1883.

Liu, J. F.; Nakatani, K.; Mizuyama, T. (2013): Effect assessment of debris flow mitigation works based on numerical simulation by using Kanako 2D. Landslides, vol. 10, no. 2, pp. 161-173.

Lombardo, L.; Opitz, T.; Huser, R. (2018): Point process-based modeling of multiple debris flow landslides using INLA: an application to the 2009 Messina disaster. Stochastic Environmental Research and Risk Assessment, vol. 32, no. 7, pp. 2179-2198.

Luna, B. Q.; Remaitre, A.; Van Asch, Th. W. J.; Malet, J. P.; Van Western, C. J. (2012): Analysis of debris flow behavior with a one dimensional run-out model incorporating entrainment. Engineering Geology, vol. 128, pp. 63-75.

Malet, J. P.; Laigle, D.; Remaitre, A; Maquaire, O. (2004): Triggering conditions and mobility of debris flows associated to complex earthflows. Geomorphology, vol. 66, no. 1-4, pp. 215-235.

Medina, V.; Huerlimann, M.; Bateman, A. (2008): Application of FLATModel, a 2D finite volume code, to debris flows in the northeastern part of the Iberian Peninsula. Landslides, vol. 5, no. 1, pp. 127-142. 
Ouyang, C. J.; He, S. M.; Tang, C. (2015): Numerical analysis of dynamics of debris flow over erodible beds in Wenchuan earthquake-induced area. Engineering Geology, vol. 194, pp. 62-72.

Papa, M. N.; Sarno, L.; Vitiello, F. S. (2018): Application of the 2D depth-averaged model, FLAT Model, to pumiceous debris flows in the Amalfi Coast. Water, vol. 10, no. 9, pp. 1159-1165.

Rematre, A; Malet, J. P.; Maquaire, O. (2005): Flow behavior and runout modelling of a complex debris flow in a clay-shale basin. Earth Surface Processes and Landforms, vol. 30, no. 4, pp. 479-488.

Richard, M. I.; Mark, E. R.; Richard, G. L. (1997): Debris-flow mobilization form landslide. Annual Review of Earth and Planetary Sciences, vol. 25, no. 1, pp. 85-138.

Rickenmann, D.; Zimmermann, M. (1993): The 1987 debris flows in Switzerland: documentation and analysis. Geomorphology, vol. 8, no. 2-3, pp. 175-189.

Savage, S. B.; Hutter, K. (1989): The motion of a finite mass of granular material down a rough incline. Journal of Fluid Mechanics, vol. 199, pp. 177-215.

Scaringi, G.; Fan, X. M.; Xu, Q.; Liu, C.; Ouyang, C. J. et al. (2018): Some considerations on the use of numerical methods to simulate past landslides and possible new failures: the case of the recent Xinmo landslide (Sichuan, China). Landslide, vol. 15, no. 7, pp. 1359-1375.

Schraml, K.; Thomschitz, B.; McArdell, B. W. (2015): Modeling debris-flow runout patterns on two alpine fans with different dynamic simulation. Natural Hazards and Earth System Science, vol. 15, no. 1, pp. 1483-1492.

Vagnon, F.; Pirulli, M.; Yague, A. (2019): Comparison of two depth-averaged numerical models for debris flow runout estimation. Canadian Geotechnical Journal, vol. 56, no. 1, pp. 89-101.

Van Westen, C. J.; Van Asch, T. W. J.; Soeters, R. (2006). Landslide hazard and risk zonation-why is it still so difficult? Bulletin of Engineering Geology and the Environment, vol. 65, no. 2, pp. 167-184.

Vasu, N. N.; Lee, S. R.; Lee, D. H.; Park, J. Y.; Chae, B. G. (2018): A method to develop the input parameter database for site-specific debris flow hazard prediction under extreme rainfall. Landslide, vol. 15, no. 8, pp. 1523-1539.

Valentino, R.; Barla, G.; Montrasio, L. (2008): Experimental analysis and micromechanical modelling of dry granular flow and impacts in laboratory flume tests. Rock Mechanical Rock Engineering, vol. 41, no. 1, pp. 153-177.

Voellmy, A. (1955): Uber die Zerstörungskraft von Lawinen. Schweiz. Bauztg, vol. 73, pp. 212-217.

Xiong, M. Q.; Wang, S. Y.; Li, Y. J.; Chen, G. (2016): Effectiveness of debris flow mitigation strategies in mountainous regions. Progress in Physical Geography, vol. 40, no. 6, pp. 768-793. 